\title{
Caracterización de la segregación residencial socioeconómica 1990-2005. Evidencia
} para la ciudad de Ibagué, Tolima, Colombia*

\author{
Alexandra López Martínez`
}

\author{
Tesis de Maestría \\ Maestría en Economía \\ Universidad Nacional de La Plata
}

Directora de Tesis: María Lorena Garegnani

Junio 2019

Códigos JEL: R10, R12, Z13

\footnotetext{
* El presente trabajo se realizó bajo dirección de la Dra. Lorena Garegnani, el cual tuvo como resultado la tesis de la Maestría en Economía de la UNLP, a ella le agradezco el apoyo y sobre todo la paciencia que me tuvo durante todo este tiempo, a su vez su aliento y guía en este proceso. A la profesora Graciela del Carmen Fernández de Córdova Gutiérrez de la Pontificia Universidad Católica de Perú, a los asistentes al seminario de tesis de la Maestría en Economía de la UNLP por sus valiosos aportes y a mi papá Q.E.P.D y familia. Los posibles errores que se pudieran dar son de mi responsabilidad.

- Economista, candidata a Doctora en Estudios Territoriales de la Universidad de Caldas. Becaria del Proyecto Formación de Talento Humano de Alto Nivel de la Universidad del Tolima, Gobernación del Tolima y la Universidad de Ibagué- Integrante del Grupo Interdisciplinario de Estudios sobre el Territorio "Yuma íma" de la Universidad del Tolima. Contacto: alexanlm87@gmail.com
} 
Caracterización de la segregación residencial socioeconómica 1990-2005. Evidencia para la ciudad de Ibagué, Tolima, Colombia

\title{
RESUMEN
}

Como consecuencia de las transformaciones económicas de un nuevo paradigma económico basado principalmente en la entrada en vigor del neoliberalismo, las dinámicas de la estructura urbana a partir de la década de los años noventa del siglo XX, han traído consigo una nueva expresión de la segregación residencial. Por lo tanto el objetivo principal del presente documento es el análisis del fenómeno de segregación residencial acaecido en el municipio de Ibagué entre 1990 y 2005 a partir de microdatos censales, realizando una contribución metodológica al análisis de este fenómeno, al desarrollarse un análisis multiescalar, multidimensional y comparativo el cual está apoyado en indicadores espaciales y no espaciales que permitan representar y analizar las diferencias socio espaciales en la ciudad de estudio.

Palabras clave: segregación residencial, autocorrelación espacial, diferenciación residencial.

JEL: R10, R12, Z13

\section{Characterization of socioeconomic residential segregation 1990-2005. Evidence for} the city of Ibagué, Tolima, Colombia

\begin{abstract}
As a result of the economic transformations of a new economic paradigm based mainly on the entry into force of neoliberalism, the dynamics of the urban structure in the 1990s of the twentieth century, have brought with it a new expression of residential segregation. Therefore the main objective of this document is the analysis of residential segregation phenomenon occurred in the municipality of Ibagué between 1990 and 2005 from census microdata, making a methodological contribution to the analysis of this phenomenon, to develop a multiscale, multidimensional analysis and comparative, which is supported by spatial and non-spatial indicators that allow to represent and analyze socio-spatial differences in the city of study.
\end{abstract}

Keywords: residential segregation, spatial autocorrelation, residential differentiation.

JEL: R10, R12, Z13 


\section{Introducción}

De acuerdo al informe Panorama Social de América Latina, para el 2015 América Latina fue la región con mayor desigualdad en el mundo y Colombia ocupaba el segundo puesto en este tema (CEPAL, 2017). Teniendo en cuenta que la segregación residencial es un efecto de las desigualdades socioeconómicas, las cuales al tener una expresión en el territorio ponen en evidencia información sobre la distribución diferencial de los grupos poblacionales; el estudio de la segregación residencial en Colombia es importante en el sentido que es un fenómeno que ocurre no sólo en ciudades metropolitanas sino también en ciudades intermedias como Ibagué, ciudad que se encuentra entre las 57 de esta clasificación en donde viven cerca del 31\% de la población colombiana (Torres \& Caicedo, 2015). Es de resaltar la importancia que tienen las ciudades intermedias, que en contraste con las ciudades capitales, no se puede decir que estas por su gran tamaño vayan a dejar de ser promotoras del desarrollo económico del país en relación a las primeras, lo que sí se puede indicar, es que en las ciudades intermedias es posible la no replicación de los efectos negativos que ha traído consigo el desarrollo de las ciudades metropolitanas en las que las distancias del lugar de trabajo a la casa cada vez son más largas, los precios del suelo y de la vivienda son más altos a través del tiempo, las desigualdades socioeconómicas son más evidentes, entre otros efectos.

En este trabajo se aborda el estudio de la segregación residencial socioeconómica entre 1990 y 2005 en Ibagué, porque el interés de esta investigación nace en el interrogante ¿Las ciudades intermedias responden a la misma lógica segregativa que las grandes ciudades?. Por lo tanto, el aporte será el análisis multiescalar, multidimensional y comparativo (intercensal) apoyado en los índices no espaciales y espaciales de segregación en Ibagué, Colombia, teniendo en cuenta que para este país hay solo dos estudios (Celis, 2010; Giraldo, 2016) que abordan el fenómeno y no realizan el análisis comparativo que aquí se plantea y solo tienen en cuenta la dimensión socioeconómica y no las dimensiones

habitacionales y espaciales como abordaje multidimensional de la segregación (Lan \& Linares, 2007) y tampoco lo hacen a diferentes escalas geográficas (sector, sección y manzana) que en este documento si se desarrollan.

De acuerdo a lo anterior, la contribución de este trabajo a la literatura existente se da en varias vías. Primero, se aporta a la literatura de la segregación residencial pretendiendo 
caracterizar y cuantificar los niveles de segregación de una ciudad intermedia desde distintas escalas geográficas con el fin de corroborar la existencia de una nueva expresión de la segregación. Segundo, a diferencia de las investigaciones realizadas en este tipo de ciudades, que analizan en un solo año específico la segregación, en este trabajo se analiza entre dos cortes de tiempo, lo que permite evidenciar en dónde se localizan para cada año los distintos grupos poblacionales en estudio y cuáles han sido los cambios que han tenido en cuanto a niveles de segregación concierne es decir, quiénes se segregan más o menos de un año a otro. Tercero, el análisis se hace no sólo desde la dimensión socioeconómica, también lo hace desde la espacial y habitacional en una ciudad intermedia colombiana, en donde la literatura de segregación desde este abordaje multidimensional es nula. Por último, se contrasta los resultados de los índices no espaciales y los espaciales, validando la metodología, de tal manera que arroja resultados no sólo de en cuanto están segregadas las personas en estudio, si no también, si lo hacen de manera aleatoria o no y en donde se localizan.

Se espera también contribuir con los resultados de este estudio a la elaboración de una propuesta integral para la toma de decisiones políticas en el municipio, con el fin de aportar a una justicia espacial. De esta manera es importante estudiar la distribución socioespacial de los grupos poblacionales en dos periodos en la ciudad de Ibagué a partir de la espacialización de las variables de estudio; a su vez los niveles de segregación en términos de concentración espacial y la homogeneidad social a partir de las dimensiones socioeconómicas, habitacionales y espaciales; y la presencia de aglomeraciones espaciales que indiquen una distribución aleatoria o no entre los grupos sociales vecinos en el espacio urbano. Para ello se utilizan los censos poblacionales de 1993 y 2005 teniendo presente que el fenómeno en mención afecta a todos los estratos socioeconómicos y por ello se hace referencia a la ciudad como un todo.

Además de estar en función de los censos, se escoge este periodo de tiempo porque, desde la década de los noventa del siglo XX se pasa a adoptar el modelo neoliberal mediante el cual se transforma la economía a través de la globalización, donde la entrada en vigor del neoliberalismo promovió la liberalización y desregulación del uso del suelo, en donde el capital privado en el mercado inmobiliario juega un papel importante en el desarrollo urbano y a su vez de la expansión urbana. Por consiguiente, la adopción de este 
modelo, ha tenido efectos en el cambio de una ciudad compacta a una ciudad dispersa, transformando al territorio y a las funciones de las grandes ciudades; por lo tanto esta fragmentación de la ciudad se caracteriza por la diferenciación del espacio a través de aglomeraciones de personas con características internas homogéneas pero dispares entre sí, modificando a pequeña escala la expresión de la segregación y concentrando a los grupos poblacionales de ingresos altos en conjuntos cerrados y en zonas que antes no estaba caracterizada por la localización de estos (Ortiz, Escolano, \& Moreno, 2017).

También es a partir de esta década en donde el modelo tradicional de segregación (Pereyra, 2006) empieza a cambiar a uno nuevo de manera lenta en ciudades intermedias a diferencia de como estaba sucediendo en ciudades metropolitanas de Latinoamérica, en el que la alta concentración poblacional por clase se va rompiendo (Fernández de Córdova, 2012), situación que actualmente se corrobora en la zona nororiental y suroriental de la ciudad de Ibagué en la que se encuentra mayor diversidad socioeconómica con viviendas entre los estratos del uno al seis.

Así mismo, la aparición de nuevas centralidades en la ciudad (Bäbr \& Borsdorf, 2005; Janoschka, 2002), además del centro tradicional, empezaron a surgir a partir del año 2005. La nueva centralidad se fue construyendo alrededor de barrios en los que habitaban grupos poblacionales de condición social y económica alta, según la vigencia del Plan de Ordenamiento Territorial -POT- del 2000; a esta centralidad la circunda la denominada "milla de oro" o calle 60 ubicada en la comuna cinco (ver figura 1), donde se gestó toda la dinámica de centros comerciales, almacenes de cadena, construcción de conjuntos residenciales para la clase social media-alta, por lo tanto lo que se puede decir es que el POT anterior apoyaba la segregación voluntaria del grupo social alto y lo que sucede con el POT del 2014 vigente es que la ratifica, esto es, la refuerza más no la mitiga.

Por lo anterior, se puede indicar que es a partir de la relación entre el precio del suelo y el poder adquisitivo se genera restricciones al acceso del suelo, por lo que el acceso diferenciado a la ciudad se da desde que la industria ha convertido al suelo en una mercancía, suceso que se da en un modelo de producción capitalista, en el cual el Estado pasa de tener el rol de benefactor a uno de regulador del mercado (a través de normas y leyes) que interviene en el desarrollo urbano (Janoschka, 2002; Sabatini, Cáceres, \& Cerda, 2001; C. Torres et al., 2009; Valdés, 2007). De esta manera, pasa "que un desequilibrio 
diferencial en la forma espacial de la ciudad puede redistribuir el ingreso. En general, la persona rica en recursos puede obtener beneficios, mientras que la persona pobre y necesariamente inmóvil sólo cuenta con posibilidades restringidas” (Harvey, 1977).

En el caso de la ciudad de Ibagué, para determinar en donde se van a localizar los desarrollos urbanos según los tipos de viviendas de interés prioritario (VIP), de interés social (VIS) y las que son NO VIS se debe conocer cuál ha sido la asignación del suelo a partir del POT. Para el caso de Ibagué, en el POT del 2000 se indica que la expansión de la zona urbana de Ibagué estaba proyectada en la zona nororiental y suroriental de la ciudad. Al igual que la zona de expansión, los proyectos VIS y NO VIS estaban proyectados en la ciudad de acuerdo al POT del 2000 en las zonas nororiental y suroriental de la ciudad. Para el periodo entre 1997 y 2007 la dinámica del urbanismo para NO VIS fue predominante, teniendo en cuenta que lo que se aprobó por cada metro cuadrado para VIS fue cerca de la tercera parte de lo aprobado para vivienda NO VIS, por lo tanto por cada m2 para VIS se aprobaron 7,14 m2 para NO VIS (Clavijo, 2009).

Es así como se puede indicar que para Ibagué en el periodo de estudio, aplica que con el paso del tiempo los usos de los espacios van cambiando y las políticas de ordenamiento urbano se apoyan en criterios tanto políticos como económicos, es así como el valor desigual del suelo va diferenciando la población de acuerdo al tipo de residencia que tiene, por lo tanto se encuentra con que detrás de esta diferenciación está el mercado inmobiliario el cual da en la residencia un tipo de distinción social, distinción que se da con la posesión de capital.

La tesis está compuesta por cinco partes además de esta introducción, seguida de la revisión de los aportes teóricos y metodológicos en el que se evidencia la importancia de analizar este tema en ciudades intermedias y en especial en Colombia, al ser un tema poco recabado en este tipo de ciudades. En la sección tres y cuatro darán cuenta de las variables y fuentes que servirán de insumo para la medición de la segregación y sus respectivos resultados en donde se expresará a través de índices y además de mapas la espacialización de las variables socioeconómicas, habitacionales y espaciales de la ciudad y por último se concluye. 


\section{Antecedentes Teóricos y Metodológicos}

\subsection{Antecedentes Teóricos}

El concepto de segregación se conoce como la aglomeración de grupos poblacionales que internamente comparten características socioeconómicas homogéneas, pero que son dispares entre grupos. Este fenómeno ha sido abordado desde la diferenciación por localización y como acceso desigual.

La segregación como diferencia de localización de un grupo con respecto a otro, es acuñado a Robert Ezra Park y Ernest Burges desde la corriente Ecología Social Clásica de la Escuela de Chicago a principios del Siglo XX, concepto que se utilizó para estudiar la "concentración natural" de la población urbana por lo que la segregación no se estudió como fenómeno ni proceso urbano, se abordó desde la Ecología urbana como un concepto neutral al analizar la diferenciación espacial de las ciudades (Salas Vanegas, 2008). Para la década de los años cincuenta del siglo XX el estudio de la estructura urbana y de la segregación socioespacial desde un enfoque cuantitativo se dio en la corriente Ecología Social Moderna donde sus principales exponente fueron Shevky y Wiliams (1949) y Shevky y Bell (1955) los cuales categorizaron a la población por rango social (situación económica), urbanización (situación familiar) y segregación (grupos étnicos) (Buzai, 2003, p. 43); para estudiar la diferenciación y estratificación social de un grupo social específico a través de técnicas multivariadas.

Posteriormente, la segregación como acceso desigual toma importancia a partir de la década de los años setenta. La segregación residencial para los teóricos clásicos (Lefebvre, Lojkine y Castells) coinciden en que ésta es un estilo de organización del espacio en sociedades capitalistas (como lo toman Sabatini y Rodríguez), sin embargo el Filósofo Lefebvre $(1976,1978 \mathrm{a}, 1978 \mathrm{~b})$ lo interpretó de manera distinta a la perspectiva del Sociólogo Lojkine (1979) porque, para este autor dicho concepto es el que orienta un trabajo investigativo mientras que para Lefebvre no lo era, solo consistía en una categoría implícita en la producción y apropiación del espacio. Por su parte, Manuel Castells (2008) define la segregación urbana a partir de dos dimensiones por un lado de condición, porque se organizan en el espacio los grupos poblacionales que internamente son homogéneos y que son dispares socialmente y por el otro como proceso, porque esas diferencias 
socioeconómicas a través del tiempo tienden a ser permanentes porque se encuentran inmersas en una distribución desigual de oportunidades y de beneficios en la población.

Sin embargo, la segregación residencial no es un fenómeno solo de las sociedades capitalistas, su expresión ha cambiado en las ciudades según la época en la que se le estudie. Es así como se han identificado dos expresiones de este fenómeno (ver tabla 1), una consiste en un patrón tradicional el cual parte de un modelo de diferenciación residencial concéntrico en forma de anillos de finales del siglo XIX, en el que a medida que aumenta el anillo disminuye la clase social de la población. En la primera mitad del siglo $\mathrm{XX}$ se pasa a un modelo orientado a un crecimiento lineal del centro que se determinó por la presencia de zonas industriales y en el mismo sentido se localizaba la población por condición social alta es decir, de manera lineal desde el centro en forma de cono (Espinosa, 1992; Sabatini \& Cáceres, 2005) y los grupos sociales de condición baja más segregados en la periferia. No obstante, la nueva expresión de la segregación se dio a partir de la entrada en vigor del neoliberalismo cuando se convirtió al suelo aún más en una mercancía, suceso en el cual el Estado sigue teniendo un rol de regulador (a través de normas y leyes), pero interviniendo con un mayor énfasis en el mercado inmobiliario (Janoschka, 2002; Moura, 2003; Sabatini \& Cáceres, 2005; C. Torres et al., 2009), expresión que ha cambiado a través de la concentración del capital inmobiliario, el cambio en la forma de la vivienda de casa a apartamento, la casa como producto y no como bien necesario para el bienestar del ser humano, entre otros; de tal manera que la forma de cono como área concentrada de las élites pasa a estar difusa por efectos de la concentración del capital y la liberalización de los mercados de suelo (Sabatini \& Cáceres, 2005).

Tabla 1 Características de los cambios de patrones de la segregación residencial

\begin{tabular}{|l|l|l|}
\hline ÍTEM & $\begin{array}{l}\text { EXPRESIÓN TRADICIONAL DE LA } \\
\text { SEGREGACIÓN }\end{array}$ & NUEVO PATRÓN DE LA SEGREGACIÓN \\
\hline $\mathbf{1}$ & $\begin{array}{l}\text { Concentración de la población de ingresos altos } \\
\text { alrededor del centro histórico de la ciudad, } \\
\text { conocido como cono de alta renta. }\end{array}$ & $\begin{array}{l}\text { Dispersión de las élites fuera del cono de alta } \\
\text { renta, generando una expresión a menor escala } \\
\text { de la segregación. }\end{array}$ \\
\hline $\mathbf{2}$ & $\begin{array}{l}\text { Agrupación de población de ingresos bajos en } \\
\text { las zonas periféricas de la ciudad y en zonas } \\
\text { deterioradas del centro de la misma. }\end{array}$ & $\begin{array}{l}\text { Surgimiento de subcentros comerciales y locales } \\
\text { comerciales y de servicios fuera del Centro y en } \\
\text { general de los barrios de población de ingresos } \\
\text { altos, con el fin de conseguir extensas áreas de } \\
\text { mercado. }\end{array}$ \\
\hline
\end{tabular}




\begin{tabular}{|l|l|l|}
\hline 3 & $\begin{array}{l}\text { Relevante diversidad de grupos sociales de } \\
\text { ingresos medios en el cono de alta renta. }\end{array}$ & $\begin{array}{l}\text { Tendencia al alza de los precios del suelo y su } \\
\text { entorno espacial urbano, generando una } \\
\text { propensión de la localización de viviendas } \\
\text { nuevas para los grupos poblacionales de } \\
\text { ingresos bajos en la periferia de la ciudad o zonas } \\
\text { aledañas. }\end{array}$ \\
\hline $\mathbf{4}$ & $\begin{array}{l}\text { Conformación de una posible ciudad "dual", en } \\
\text { la que por un lado se tiende a estigmatizar } \\
\text { aquellas zonas sin prestigio de la ciudad y por } \\
\text { el otro, a dar importancia solo a zonas } \\
\text { modernas de la ciudad. }\end{array}$ & $\begin{array}{l}\text { Surgimiento de formas de crecimiento } \\
\text { residencial discontinuas respecto de la ciudad, } \\
\text { tanto en favor de centros urbanos menores como } \\
\text { de la ocupación rural. }\end{array}$ \\
\hline $\mathbf{5}$ & $\begin{array}{l}\text { Abordaje de la segregación a gran escala } \\
\text { geográfica lo que ha forzado la imagen de } \\
\text { ciudad "dual", a pesar de la diversidad de } \\
\text { grupos sociales de ingresos medios en el cono } \\
\text { de alta renta. }\end{array}$ & $\begin{array}{l}\text { Procesos de renovación urbana de áreas centrales } \\
\text { procurando por aquellas casas antiguas } \\
\text { deterioradas, con las que se logre de nuevo un } \\
\text { uso residencial o uno nuevo terciario. }\end{array}$ \\
\hline
\end{tabular}

Fuente: En base a Sabatini (2003) y Sabatini y Cáceres (2005)

En efecto, el Economista Pedro Ábramo (Ábramo, 2003) manifiesta que son los procesos y la definición del uso del suelo los principales causantes de la tomas de decisiones de localización de las personas, las cuales generan una distribución espacial segmentada y segregada de equipamientos, servicios públicos y clases sociales. Es así como, plantea que la toma de decisiones de localización de la vivienda está mediada por las dimensiones de mercado, Estado y necesidad; en especial la necesidad de la población más vulnerable, que a causa de una situación de pobreza de un grupo poblacional decide acceder a un terreno o no para autoconstruir su vivienda (Ábramo, 2003). En esta elección intervienen tres agentes (Ábramo, 2003): el Estado, el mercado y la población; los tres están en concordancia con la dimensión Espacial -Estado-, la dimensión habitacional -mercado- y la dimensión socioeconómica - población-. De este modo se puede indicar que las causas principales de la segregación están relacionadas con la acción de estos agentes, en el mercado interactúan por un lado los demandantes del suelo que son los promotores inmobiliarios los cuales influyen en la producción del espacio urbano, esto lleva a que la segregación residencial se intensifique a causa de una mayor producción de desarrollos inmobiliarios para demandantes potenciales de ingresos altos y no de ingresos bajos, los primeros tendría mayor oportunidad al acceso de vivienda digna además del valor agregado que el promotor inmobiliario le ofrece, diferente el caso de la población de condición social baja, estos autoconstruyen sus viviendas en terrenos y con materiales que se ajuste a su situación económica. Por su parte, el Estado como oferente del derecho al 
suelo, juega un papel de incentivador desde la demanda de vivienda a través de los subsidios para adquirirla, principalmente a partir de la década de los noventa.

Por otro lado, las posibles consecuencias de la segregación residencial socioeconómica que al tener una definición compuesta, puede generar efectos tanto positivos como negativos. Los efectos positivos darán indicios de cómo la concentración espacial de un grupo social podría llegar a encaminar políticas públicas eficientes; los efectos negativos conllevan a la separación de grupos socialmente homogéneos internamente y que además se distinguen (Sabatini, 2003), y la estigmatización territorial que se da por la disputa de quien posee el capital suficiente para escoger el espacio del que se quiere apropiar y que promueve la segregación según sus condiciones socio-económicas.

Finalmente, se puede indicar que en la producción del espacio urbano se presenta una acumulación capitalista convirtiéndose en una mercancía, en la cual se impone un estilo de vida de acuerdo al valor de cambio y no de uso que se le da al mismo, así, la población accederá a una vivienda en la ciudad de acuerdo a sus ingresos generando una diferenciación tanto social como del espacio. De esta manera, la población se segrega y se generaliza la percepción de que este es un fenómeno más negativo que positivo en la vida urbana (Alessandri, 2013), es decir, "el espacio de la ciudad capitalista es fuertemente dividido en áreas residenciales "segregadas", reflejando la compleja estructura social en clases" (Corrêa, 1989, p. 8) [traducción del autor].

\subsection{Antecedentes Metodológicos}

El estudio de la segregación residencial ha sido abordado de distintas perspectivas en diferentes países. Para el caso de los Estados Unidos el fenómeno de la segregación residencial se ha abordado desde el punto de vista racial (Jargowsky, 1996) y en España se le ha estudiado desde la población inmigrante (Martori i Cañas \& Hoberg, 2004; Martori, Hoberg, \& Surinach, 2006b). Un hallazgo particular en los estudios europeos es que los índices de segregación residencial no espaciales arrojan valores más altos que aquellos resultados de los índices de segregación residencial espaciales, lo que indica que el nivel de segregación puede ser sobrevalorado de acuerdo a la herramienta que se utilice para su estimación. 
Para Latinoamérica se ha abordado el estudio de la segregación residencial más desde la perspectiva socioeconómica en países como Costa Rica (Pujol M, Sánchez H, \& Pérez M, 2011), México (Aguilar \& Mateos, 2011; Fuentes \& Hernández, 2013; García de la Rosa, 2011; Monkkonen, 2012), Brasil (Feitosa, 2005; Marmolejo \& Batista-Dória, 2011) y Argentina (Groisman \& Suárez, 2006; Lan \& Linares, 2007; Linares, 2010; Molina, 2008; Molinatti, 2013; Prieto, 2012; Prieto \& Formiga, 2010, 2011). Los resultados más relevantes de estos trabajos son: la concentración poblacional en conjuntos cerrados es alta a causa de una autosegregación principalmente por personas con ingresos altos; en el caso de las ciudades intermedias, la segregación poblacional presenta patrones de autocorrelación espacial similares al de las ciudades metropolitanas porque, en el norte se localizan grupos poblacionales de altos niveles educativos y al sur los grupos poblaciones con niveles educativos bajos y, que el nivel educativo del jefe del hogar es un determinante de segmentación fuerte, el cual al relacionarse con la prestación de servicios precarios y la condiciones precarias de socio habitabilidad, intensifican el nivel de segregación en la población.

Cabe aclarar, que el enfoque metodológico de Massey \& Denton (1988) desde lo planteado por Linares (2010) y otros autores (Garrocho \& Campos-Alanís, 2013; Jargowsky, 1996; Johnston, Poulsen, \& Forrest, 2007; Reardon \& O’Sullivan, 2004; RuizTagle \& López, 2014; Sabatini \& Sierralta, 2006; Watts, 2005), no es propiamente útil para determinar niveles de segregación en ciudades Latinoamericanas. Esto se debe a que en esta región, la élite se ubica en el centro de la ciudad y la población de bajos ingresos en la periferia y en zonas suburbanas (de manera especial antes de los 90's); mientras que para el caso de Estados Unidos el patrón de segregación se comporta de manera inversa. Sin embargo, después de la década de los 90's con la reducción de la participación del Estado promovió la mayor participación por parte del sector privado (inmobiliarias, el sector financiero y de la construcción, entre otros) en la producción de vivienda, fomentando el crecimiento urbano desde la perspectiva comercial con fines en el mercado (De Mattos, 2002; Janoschka, 2002).

En cuanto a Colombia, se encuentra que se ha estudiado la segregación residencial más desde su perspectiva económica desde las dimensiones planteadas por Massey \& Denton (1988) y en menor medida desde los precios del suelo en Bogotá (Fuentes Durán, 
2010), la vivienda social en Medellín (Velasquez, 2011), el desarrollo urbano y la segregación en el municipio de Barrancabermeja (Molina, 2008). Los resultados relevantes que se encuentran para ciudades metropolitanas como Bogotá desde los índices no espaciales es que el precio de la vivienda y el estrato socioeconómico analizado a escala localidad acentúan la segregación y, que la escala geográfica es un factor relevante para no subestimar los niveles de segregación ya que a menor escala mayor segregación.

Por su parte, a partir de análisis de autocorrelación espacial se encuentran que existe segregación cuando la variable avalúo, el capital humano y el promedio de años de educación tiene una dependencia espacial (Aliaga \& Álvarez, 2010; Medina, Morales, \& Núñez, 2008; Vivas, 2011, 2012). Por lo tanto, algunos autores (Ríos, 2010; Secretaría Distrital de Planeación, 2007, 2011, 2013) plantean que las políticas públicas deben ir encaminadas a reducir los efectos tanto excluyentes como discriminatorios de la segregación para que la brecha entre ricos y pobres se reduzca.

Para los estudios de caso de segregación residencial en ciudades intermedias se encuentra que la ciudad de Manizales se segrega más por barrios que por comunas al igual que la ciudad de Bogotá (Celis, 2010). En cuanto al modelo de correlación espacial se encontró no solo la existencia de aglomeraciones de barrios pobres en relación a indicadores sociales de segregación sino que además se evidenció que los pobres además de segregarse se están concentrando locamente, es decir se alejan de los barrios no pobres dificultando así la integración social. No obstante, para el caso de Tunja el patrón segregativo difiere de Manizales en el sentido que la dinámica del fenómeno es más disperso explicado por la lenta dinámica de los desarrollos urbanos en comparación con las ciudades principales de América Latina (Giraldo, 2016).

Por último, para el caso de Ibagué no se encontró evidencia directa en la que se corrobore existencia de segregación residencial en la ciudad desde la perspectiva socioeconómica, no obstante, a partir de estudios etnográficos se concluye que la localización de la vivienda de la población con niveles socioeconómicos altos y bajos al no estar polarizada de manera tajante no se evidencia segregación residencial socioeconómica (Torres et al., 2009). Por su parte, los trabajos de Vargas, et al (2010) y Vargas y Jiménez (2013), manifiestan que la existencia de asentamientos humanos se relaciona con el fenómeno segregación residencial. Se puede concluir que para la ciudad de Ibagué hay poca 
bibliografía acerca de la configuración del espacio a partir del crecimiento urbano y que no existe evidencia empírica que indique si la población de Ibagué se encuentra segregada o no es decir no se encontraron investigaciones que hayan abordado la segregación residencial desde ninguna de sus dimensiones (objetiva ni subjetiva), por lo tanto tampoco no hay estudios comparativos año a año, ni para la ciudad, ni para el departamento del Tolima.

En concordancia a la revisión de los antecedentes son dos expresiones de la segregación, que al analizarse desde la perspectiva de la escala de grado, se encontró que la posición social de los sujetos estaba determinada en el patrón tradicional de la segregación es decir, por la distancia de acuerdo a la ubicación del centro tradicional (Bäbr y Borsdorf, 2005), pero en la nueva expresión de este fenómeno lo que se evidencia es que la posición social ya no es determinada por la posición geográfica, como se muestra en la tabla 1, porque se han desarrollado nuevas lógicas de separación a través de las fronteras que permiten aglomerar a los grupos poblacionales de acuerdo a atributos en común y a su nivel social. Por lo tanto, es necesario analizar la segregación no solo para ciudades metropolitanas sino también para las intermedias ya que, la existencia de clases sociales y su posición relativa con respecto a otros y las prácticas de estas en el territorio, pueden generar patrones segregativos distintos de acuerdo al tiempo y espacio en el que se estudie. Por lo tanto, los efectos de un fenómeno como la segregación no solo se expresan en el ordenamiento espacial de los sujetos sino también en el ordenamiento social porque, son los sujetos los que conforman los lugares y le otorgan sentido a ese territorio que habitan, en este sentido es también el aporte de este trabajo a la literatura existente.

\section{Metodología de Investigación: Variables y fuentes}

La segregación residencial surge en la ciudad y su patrón de comportamiento es distinto según la época en la que se estudie y su nivel será diferente según la escala geográfica que se elija. Entonces dada la naturaleza del problema de investigación y los objetivos planteados, el trabajo se adelanta con base en métodos cuantitativos.

Ibagué es una ciudad con una población aproximada de 553.524 habitantes en el 2015 de acuerdo al Informe de Ibagué Cómo Vamos, 2015. Su población se encuentra distribuida político administrativamente en 13 comunas que se dividen en 4 zonas, la zona noroccidental conformada por las comunas 1, 2, 3 y 4, la zona nororiental comprendida por 
las comunas 6,7 y 8 , la zona suroriental en las que se encuentra las comunas 5 y 9 y por último las comunas 10, 11, 12 y 13 conforman la zona suroccidental (Ver Figura 1).

Para este documento se utilizó como fuente secundaria los microdatos de los Censos de Población de 1993 y 2005 para la ciudad de Ibagué, realizada por el Departamento Administrativo Nacional de Estadística (DANE) a 338.633 personas en 1993 y a 465.859 personas para el 2005. Esta información para el primer año no está disponible de manera pública y para el segundo censo a la escala más pequeña no fue posible obtenerla a partir del sistema de consulta de información censal, por lo tanto fue necesario solicitar directamente al DANE todas las variables, solicitud que tomó cerca de un año poder acceder a ella. Por su parte, la delimitación temporal se basa en dos características fundamentales la primera, es porque la disponibilidad de información censal hasta la microescala de manzana para los dos años censales; y la segunda, es que en este periodo de tiempo principalmente entra en vigor el neoliberalismo momento en que se ha convertido al suelo aún más en una mercancía, en donde el Estado ha tenido un rol de regulador principalmente a través de normas y leyes, pero con mayor intervención del mercado inmobiliario en la producción de vivienda (Janoschka, 2002; Moura, 2003; Sabatini \& Cáceres, 2005).

Figura 1. Contexto nacional, departamental y municipal del municipio de Ibagué

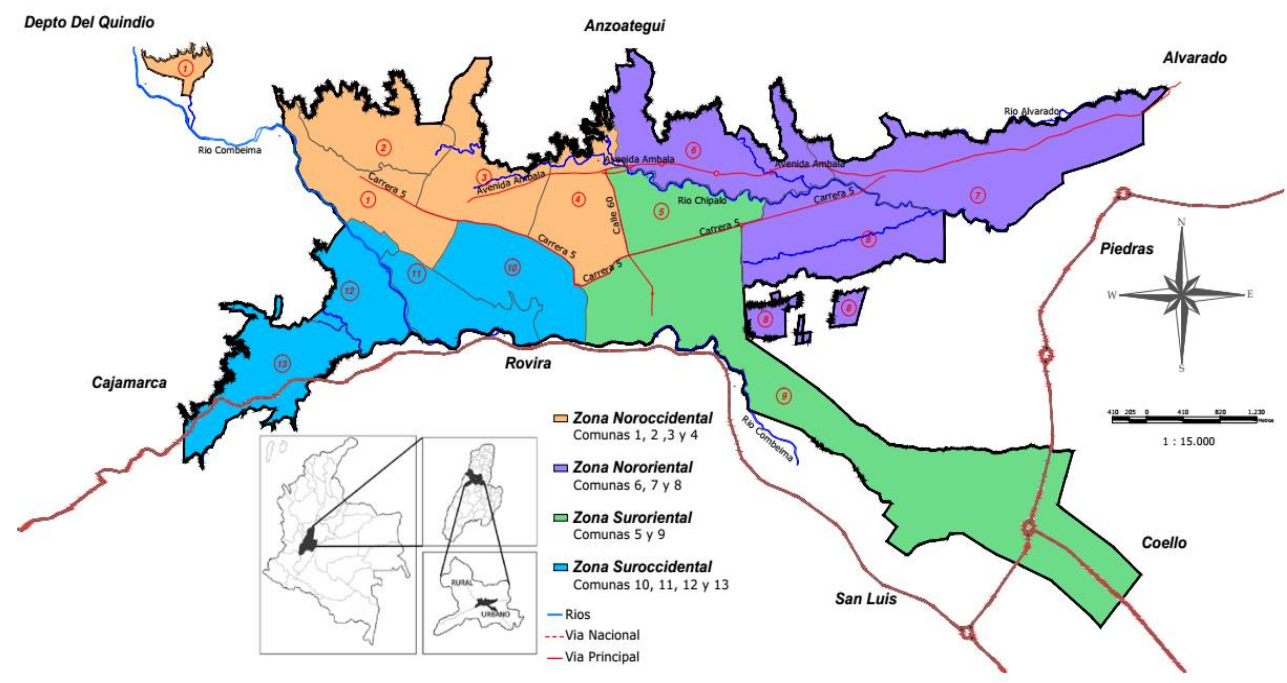

Fuente: Torres et al., (2009) y Alcaldía de Ibagué (2008) 
Por otro lado, la espacialización de las variables a través de los mapas temáticos se realizaron a partir de la extensión ArcMapc 10.1 del programa ArcGis 10.1, de esta manera los códigos censales disponibles se compatibilizaron con los códigos de la cartografía censal de Marco Geoestadístico Nacional (MGN) disponible en el DANE, esta compatibilización de códigos es nueva y la base de datos que sustenta la base cartográfica previo a este estudio no se había realizado en un estudio para Ibagué. Con esta información se tiene la posibilidad de conocer la diferenciación espacial según las escalas geográficas que corresponden al sector urbano, que es el equivalente al barrio; a la sección urbana, que es una escala más pequeña al barrio (20 manzanas), y la manzana que corresponde a un lote edificado o sin edificar previamente delimitado (DANE, s.f.). Esta capa geográfica construida en formato ESRI de shapefile, se carga en el programa Geo-Segregation Analyzer (Apparicio et al 2013), en el cual se calculan los índices no espaciales de la segregación y en el programa se sistema de información geográfica GeoDa se calculan los índices espaciales. En la tabla dos se detalla la cantidad de unidades que se van a analizar para cada escala geográfica.

Tabla 2. Unidades espaciales por cantidad en la zona urbana de Ibagué en los años 1993 y 2005

\begin{tabular}{|l|r|r|}
\hline Unidades espacial & $\mathbf{1 9 9 3}$ & $\mathbf{2 0 0 5}$ \\
\hline Sectores & 61 & 63 \\
\hline Secciones & 223 & 251 \\
\hline Manzanas & 3621 & 3706 \\
\hline
\end{tabular}

Fuente: Elaboración propia, según datos censales del DANE de 1993 y 2005

Para el análisis de la segregación espacial se tuvo en cuenta los sectores, las secciones y manzanas censales de acuerdo a la disponibilidad de información en estas escalas geográficas por lo tanto, la matriz de datos que se construyó contiene atributos espaciales de tal manera que a cada observación le correspondiera una unidad espacial de análisis. En la tabla tres se muestran cada uno de los grupos poblacionales a estudiar de acuerdo al número de personas y viviendas pertenecientes a cada uno y la participación de cada grupo con respecto a la población total por cada año censal. 
Tabla 3. Variables por grupo dimensión y grupo poblacional de Ibagué en los años 1993 y 2005

\begin{tabular}{|l|r|r|r|r|}
\hline VARIABLES & \multicolumn{2}{|c|}{1993} & \multicolumn{2}{|c|}{2005} \\
\hline Educación & Cantidad & Participación & Cantidad & Participación \\
\hline 1. Jefes que cursaron solo hasta quinto de primaria & 17105 & 5,1 & 24533 & 5,3 \\
\hline 2. Jefes que cursaron solo hasta once grado & 10687 & 3,2 & 17888 & 3,8 \\
\hline $\begin{array}{l}\text { 3. Jefes de hogar con educación técnica, tecnológica o } \\
\text { superior }\end{array}$ & 11589 & 3,4 & 25706 & 5,5 \\
\hline $\begin{array}{l}\text { 4. Menores que no asisten a alguna institución } \\
\text { educativa. (Deserción escolar) }\end{array}$ & 11308 & 3,3 & 23989 & 5,1 \\
\hline 5. Jefes de Hogar desempleados & 2094 & 0,6 & 6330 & 1,4 \\
\hline 6. Jefes de hogar sin educación formal & 4171 & 1,2 & 6497 & 1,4 \\
\hline & & & & \\
\hline $\begin{array}{l}\text { Disfuncionalidad de los servicios básicos en la } \\
\text { vivienda }\end{array}$ & & & & \\
\hline $\begin{array}{l}\text { 1. Vivienda sin conexión a la red de desagüe pública } \\
\text { (alcantarillado) }\end{array}$ & 4515 & 6,6 & 1843 & 1,6 \\
\hline $\begin{array}{l}\text { 2. Vivienda sin conexión a la red de agua corriente } \\
\text { pública (acueducto) }\end{array}$ & 582 & 0,9 & 1038 & 0,9 \\
\hline $\begin{array}{l}\text { 3. Vivienda sin conexión a la red de electricidad } \\
\text { pública (Energía eléctrica) }\end{array}$ & 2867 & 4,2 & 1135 & 1,0 \\
\hline
\end{tabular}

Fuente: Elaboración propia, según datos censales del DANE de 1993 y 2005

Las bases de datos contienen variables relacionadas con la segregación desde las dimensiones socioeconómica, habitacional y espacial, para la primera se tiene en cuenta el nivel educativo del jefe del hogar ${ }^{1}$ que cursó solo hasta quinto de primaria, jefes que cursaron solo hasta once grado, jefes de hogar con educación superior y de posgrado, jefes de hogar sin educación formal, menores de 16 años que no asisten a alguna institución educativa (Deserción escolar) y jefes de hogar desempleados. De acuerdo a distintos autores (Arriagada \& Rodríguez, 2004; Kaztman, 2003; Molinatti, 2013) la educación, además del nivel de ingresos, es una variables que diferencia a la población, la separa y la segrega, entonces se escoge la variable nivel educativo del hogar al no tener información del nivel de ingresos en ninguno de los censos mencionados y porque se puede catalogar como una variable proxy del nivel socioeconómico del hogar (Molinatti, 2013).

Por su parte, la dimensión habitacional tiene en cuenta solo la disfuncionalidad de los servicios básicos de la vivienda y no se incluyen las condiciones críticas ni las sanitarias de la vivienda debido a falta de información censal a escala manzana en el censo del 2005.

\footnotetext{
${ }^{1}$ Los niveles educativos por cada jefe de hogar no se acumulan es decir, la observación que se encuentra como jefe de hogar con educación solo hasta grado quinto de primaria no se repite en el jefe de hogar que tiene educación hasta grado once, y así en lo sucesivo.
} 
La disfuncionalidad de los servicios es un determinante habitacional de la segregación porque, permiten determinar posible autosegregación de los estratos medios y altos y expulsión de la clase social baja a determinadas zonas geográficas de la ciudad que no cuentan con estos servicios de manera adecuada y además proporciona información de las condiciones de los servicios públicos que puede considerarse un reflejo de la condición socioeconómica del jefe de hogar. En cuanto a la dimensión espacial se tuvo en cuenta el equipamiento colectivo (salud, educación, deporte y cultura), el cual es provisto por el Estado y de esta manera es el responsable del bienestar colectivo independiente de la posición social de la población.

Para cada dimensión se analiza las escalas geográficas mencionadas y se calculan los índices clásicos no espaciales desarrollados por Massey y Denton (1988) como lo son el índice de segregación y el índice de segregación ajustado por la contigüidad, aislamiento y concentración e indicadores espaciales de la segregación en el análisis multidimensional de este fenómeno. Para el análisis multidimensional se tendrá en cuenta las dimensiones económica, habitacional y espacial (Ver tabla 4).

El cómo, el por qué y el donde de la segregación residencial desde el punto de vista cuantitativo será explicado por los indicadores no espaciales y espaciales, en el primer grupo se va a trabajar con los indicadores ya nombrados. Para determinar la concentración espacial de los grupos sociales se hace uso del índice de segregación (IS) el cual mide la distribución de un grupo determinado con respecto al resto de la población (Massey \& Denton, 1988) y el índice de segregación ajustado por la contigüidad (IS(adj)) identifica la configuración espacial de las unidades a partir del índice de segregación (Morril, 1991). Sus resultados se encuentran entre cero y uno, los valores cercanos a cero significan ausencia de segregación y cercano a uno es segregación alta, también en términos porcentuales manifiestan la proporción del grupo poblacional que debe cambiar de unidad espacial para alcanzar la igualdad de la distribución (Martori et al., 2006b) y se expresan de la siguiente manera:

$$
\begin{gathered}
I S=\frac{1}{2} \sum_{i=1}^{n}\left|\frac{x_{i}}{X}-\frac{t_{i}-x_{i}}{T-X}\right| \\
T=\text { Es el total de la población en la ciudad }
\end{gathered}
$$


Tabla 4. Propuesta de variables para análisis de la segregación residencial en el municipio de Ibagué

\begin{tabular}{|c|c|c|c|c|c|}
\hline DIMENSIONES & SUBDIMENSION & VARIABLES & DESCRIPCIÓN & $\begin{array}{c}\text { ESCALA } \\
\text { GEOGRÁFICA }\end{array}$ & FUENTE \\
\hline \multirow{6}{*}{$\begin{array}{c}\text { DIMENSION } \\
\text { SIOCIO- } \\
\text { ECONOMIC } \\
\text { A }\end{array}$} & \multirow{6}{*}{ Educación } & $\begin{array}{l}\text { 1. Jefes que cursaron solo hasta } \\
\text { quinto de primaria }\end{array}$ & $\begin{array}{l}\text { Jefe de hogar con nivel de estudios y años } \\
\text { aprobados, Básica primaria completo }\end{array}$ & \multirow{14}{*}{$\begin{array}{c}\text { Escala } \\
\text { geográfica por } \\
\text { Sectores, } \\
\text { Secciones y } \\
\text { Manzanas }\end{array}$} & \multirow{14}{*}{$\begin{array}{c}\text { Censo } 1993 \\
\text { y } 2005 . \\
\text { Secretaría } \\
\text { de } \\
\text { Planeación } \\
\text { Municipal } \\
\text { de Ibagué. }\end{array}$} \\
\hline & & $\begin{array}{l}\text { 2. Jefes que cursaron solo hasta once } \\
\text { grado }\end{array}$ & $\begin{array}{l}\text { Jefe de hogar con nivel de estudios y años } \\
\text { aprobados, Media académica clásica } 11 \text { completa }\end{array}$ & & \\
\hline & & $\begin{array}{l}\text { 3. Jefes de hogar con educación } \\
\text { técnica, tecnológica o superior } \\
\end{array}$ & $\begin{array}{l}\text { Jefe de hogar con nivel de estudios y años } \\
\text { aprobados, superior y postgrado completo }\end{array}$ & & \\
\hline & & $\begin{array}{l}\text { 4. Menores que no asisten a alguna } \\
\text { institución educativa. (Deserción } \\
\text { escolar) }\end{array}$ & $\begin{array}{l}\text { Menores a } 16 \text { años que no asisten a alguna } \\
\text { institución educativa }\end{array}$ & & \\
\hline & & 5. Jefes de Hogar desempleados & $\begin{array}{l}\text { Jefes de Hogar en la que su ocupación es } \\
\text { Desempleado }\end{array}$ & & \\
\hline & & 6. Jefes de hogar sin educación formal & Jefes de hogar sin ningún nivel educativo & & \\
\hline \multirow{3}{*}{$\begin{array}{l}\text { DIMENSIÓN } \\
\text { HABITACIO } \\
\text { NAL }\end{array}$} & \multirow{3}{*}{$\begin{array}{l}\text { Disfuncionalidad } \\
\text { de los servicios } \\
\text { básicos en la } \\
\text { vivienda }\end{array}$} & $\begin{array}{l}\text { 1. Vivienda con o sin conexión a la red } \\
\text { de desagüe pública (alcantarillado) }\end{array}$ & $\begin{array}{l}\text { La vivienda que no cuenta con servicio de } \\
\text { alcantarillado }\end{array}$ & & \\
\hline & & $\begin{array}{l}\text { 2. Vivienda con o sin conexión a la red } \\
\text { de agua corriente pública (acueducto) }\end{array}$ & $\begin{array}{l}\text { La vivienda que no cuenta con servicio de } \\
\text { acueducto }\end{array}$ & & \\
\hline & & $\begin{array}{l}\text { 3. Vivienda con o sin conexión a la red } \\
\text { de electricidad pública (Energía } \\
\text { eléctrica) }\end{array}$ & $\begin{array}{l}\text { La vivienda que no cuenta con servicio de energía } \\
\text { eléctrica }\end{array}$ & & \\
\hline \multirow{5}{*}{$\begin{array}{l}\text { DIMENSIÓN } \\
\text { ESPACIAL }\end{array}$} & \multirow{5}{*}{ Ubicación } & Equipamiento por: & & & \\
\hline & & Salud & $\begin{array}{l}\text { Centros de Salud, Unidades intermedias, Clínicas y } \\
\text { Hospitales }\end{array}$ & & \\
\hline & & Educación & Instituciones educativas públicas y privadas. & & \\
\hline & & Deporte & Escenarios deportivos de nivel 1,2 y 3 & & \\
\hline & & Cultura & Expresión, memoria y cohesión & & \\
\hline
\end{tabular}




$$
\begin{gathered}
\qquad I S(A d j)=I S-\frac{\sum_{i=1}^{n} \sum_{j=1}^{n}|c i j(z i-z j)|}{\sum_{i=1}^{n} \sum_{j=1}^{n} \text { cij }} \\
x_{i}=\text { Población del grupo bajo estudio en la unidad espacial " } i \text { " } \\
X=\text { Población del grupo bajo estudio en toda la ciudad } \\
y_{i}=\text { Población del grupo de refrencia en la unidad espacial " } i " \\
Y=\text { Población del grupo de referencia en toda la ciudad } \\
\text { cij }=\text { valor de la celda de la matriz de contigüidad entre las unidades } i, j \\
z i=\text { Proporción del grupo con determinada característica en la unidad } i \\
z j=\text { Proporción del grupo con determinada característica en la unidad } j
\end{gathered}
$$

Teniendo en cuenta que estos índices de igualdad miden si un grupo presenta distribución desigual entre las unidades espaciales, más no la ocupación física (superficie), se analizará este tipo de concentración a través del indicador que lleva su mismo nombre, el cual explica que en "cuanto más pequeña sea la parte del espacio urbano que ocupa un grupo, más concentrado estará” (Martori, Hoberg, \& Surinach, 2006a, p. 52) a continuación se enuncia su expresión

$$
\begin{gathered}
\text { Del }=\frac{1}{2} \sum_{i=1}^{n}\left|\frac{x_{i}}{X}-\frac{a_{i}}{A}\right| \\
a_{i}=\text { Superficie de la unidad espacial " } i " \\
A=\text { Superficie de toda la ciudad }
\end{gathered}
$$

Por su parte, para determinar la homogeneidad social de las diferentes áreas se hace uso del Índice de Aislamiento $(x P x)$ el cual mide la probabilidad que tiene un grupo de interactuar o exponerse a su mismo grupo social compartiendo su unidad espacial (Massey \& Denton, 1988), se mide de 0 a 1 y su valor máximo indica que un grupo determinado se encuentra aislado en la unidad donde habita. Debido a que este índice es sensible a la proporcionalidad de los distintos grupos, el índice de aislamiento corregido (Eta ${ }^{2}$ ajusta a los diferentes proporciones de los grupos sobre el total de la ciudad (Martori et al., 2006a). Estos índices se definen así

$$
\begin{aligned}
& x P x=\sum_{i=1}^{n}\left[\left(\frac{x_{i}}{X}\right)\left(\frac{x_{i}}{p_{i}}\right)\right] \\
& x_{i}=\text { Población del grupo bajo estudio en la unidad espacial " } i " \\
& X=\text { Población del grupo bajo estudio en la toda la ciudad }
\end{aligned}
$$




$$
\begin{aligned}
& p_{i}=\text { Población total en la unidad espacial " } i " \\
& E t a^{2}=\frac{x P x-P}{1-P} \\
& x P x=\text { Índice de aislamiento } \\
& P=\text { Proporción de población del grupo X en la ciudad }
\end{aligned}
$$

Debe tenerse en cuenta que estos índices no espaciales tienen la desventaja de no dar cuenta de la localización relativa entre las unidades espaciales (Garrocho \& CamposAlanís, 2013), considerándolas independientes en el territorio, lo que es una situación alejada de la realidad cuando no hay ciudad que no sea espacial. Esta situación en los indicadores no espaciales genera dos problemas como lo son el del tablero de ajedrez al no considerar la dimensión espacial y el del problema de la unidad espacial modificable porque no se contempla la posibilidad de asumir criterios de vecindad. Con el problema del tablero de ajedrez lo que explicarán sus resultados es que a medida que la escala de estudio sea alta el nivel de segregación será a su vez bajo, de ahí que se recomiende analizar el fenómeno a diferentes escalas geográficas (para este trabajo son sector, sección y manzana). En cuanto al problema de la unidad espacial modificable, los indicadores no espaciales asumen un espacio discreto sin contemplar límites y/o vecindad entre las unidades

De otro lado, está el problema aestadístico que presentan estos indicadores ya que no revelan significancia estadística (Garrocho \& Campos-Alanís, 2013; Linares, 2010). Es por ello que los indicadores espaciales son un complemento para el presente análisis de segregación, para ello se hará uso de los índices de autocorrelación espacial con el fin de determinar si existe una distribución aleatoria o no entre unidades vecinas con respecto a una misma variable, por ello se va hacer uso del Indicador Global de Morán (IGM) (Reardon \& O'Sullivan, 2004), índice que explica si hay aglomeraciones de grupos poblacionales en el espacio geográfico. El criterio de contigüidad seleccionado es el de reina el cual consiste en compartir al menos un vértice con frontera y este índice se expresa

$$
\begin{gathered}
I=\frac{n \sum_{i=1}^{n} \sum_{i=1}^{n} w_{i j}\left(y_{i}-y\right)\left(y_{j}-y\right)}{\left(\sum_{i=1}^{n}\left(y_{i}-y\right)^{2}\right)\left(\sum_{i \neq 1} \sum w_{i j}\right)} \\
y_{i}=\text { Valor de la variable o atributo en cada unidad espacial analizada } \mathrm{i} .
\end{gathered}
$$




$$
\begin{aligned}
& y_{j}=\text { Valor de la variable o atributo en cada unidad espacial vecina" } j \text { ". } \\
& w_{i j}=\text { Proximidad entre las unidades espaciales " } i \text { " } y \text { " } j \text { " } \\
& n=\text { número de unidades espaciales }
\end{aligned}
$$

Este índice explica si hay algún grado de dependencia entre la variable de estudio o zonas geográficas. También está el índice Local de Anselin o conocido como LISA el cual indica si esos grupos poblaciones además de aglomerarse también se concentran localmente y se expresa así

$$
I_{i}=Z_{i} \sum_{i} w_{i j} Z_{j}
$$

Donde $\mathrm{Z}_{\mathrm{i}} Z_{j}=$ Son desviaciones estándar $\mathrm{Z}_{\mathrm{i}}=\frac{\left(x_{i}-\bar{x}_{l}\right)}{\sigma}$ y $\sigma$ es la desviación estándar de $x_{i}$

\section{Resultados}

4.1 Análisis descriptivo. Distribución socioespacial de la población ${ }^{2}$.

Según la cartografía obtenida a cerca de las dimensiones socioeconómicas, habitacionales y espaciales, se observa una preferencia de ubicación de los grupos poblacionales en estudio, de ahí que se puede indicar que en la ciudad de Ibagué se establece una tendencia de segregación en concordancia con aglomeraciones relevantes de población de condiciones sociales bajas, dicho de otra manera, la distribución intraurbana evaluada a estos grupos permite evidenciar segregación residencial por localización de grupo.

Variables que evidencian problemas sociales como lo son el jefe de hogar sin nivel educativo -ver figura 2- y menores de 16 años sin asistencia a ninguna institución académica -ver figura 3-, se encuentran localizados en las zonas nororiental y suroccidental de la ciudad en las que predominan las comunas seis y 13 , en donde los barrios que prevalecen con estas características son las Delicias, la Gaviota, San Isidro, Granada, Jazmín, Boquerón y la Unión; situación que es tendencia en ambos años de estudio.

\footnotetext{
${ }^{2}$ Para el análisis de la representación de la distribución espacial de las variables de estudio, se utilizó la clasificación de datos espaciales denominado umbrales naturales (Naturales Breaks-Jenks), el cual consiste en generar rangos teniendo como límites entre ellos los valores más altos, así se logra tener en cuenta las discontinuidades de las observaciones. Por lo tanto, los valores más altos indican mayor aglomeración del grupo poblacional en estudio por cada variable.
} 
Figura 2. Jefe de hogar sin nivel educativo en Ibagué, 1993 y 2005

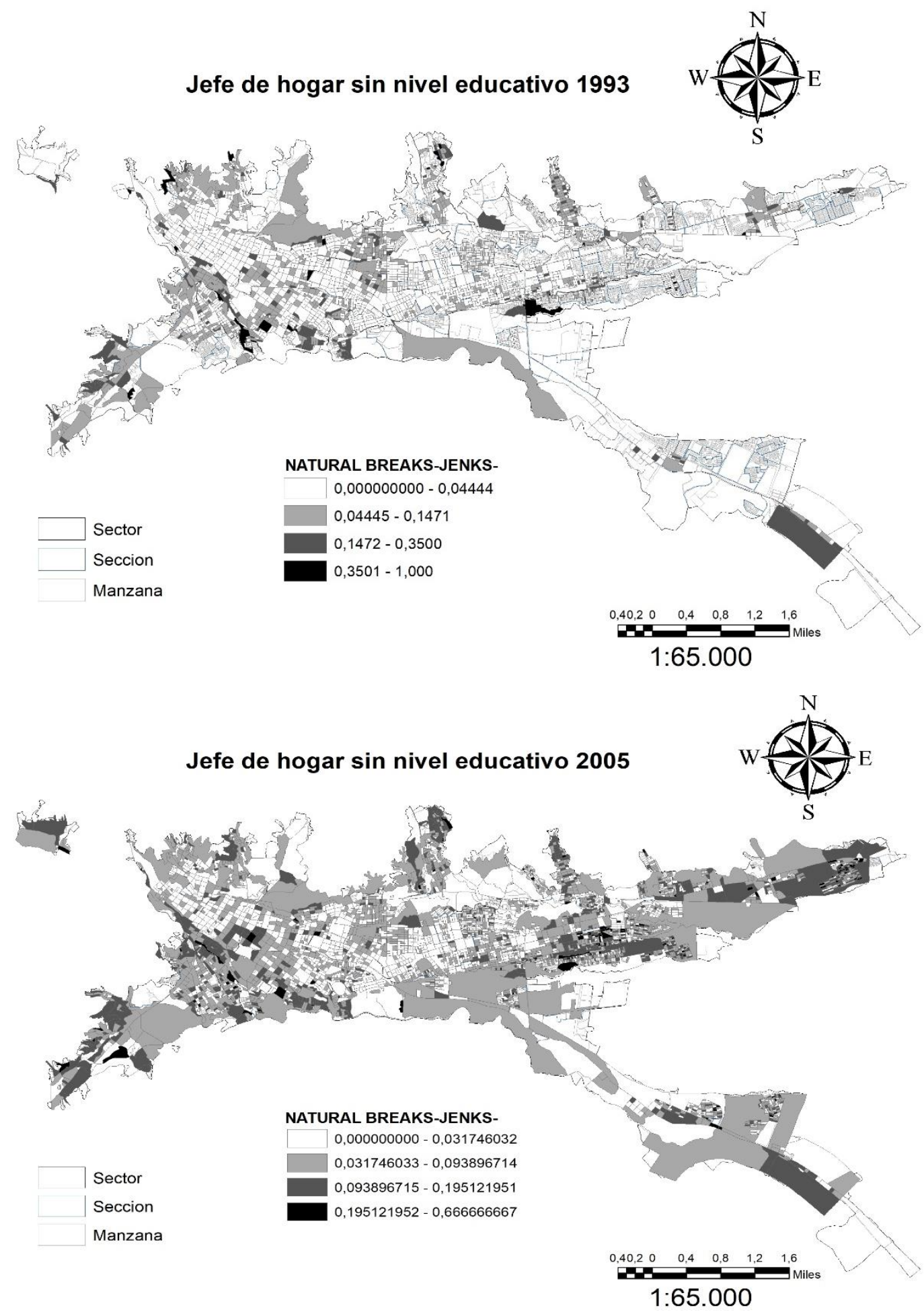

Fuente: Cartografía DANE, datos censales del DANE de 1993 y 2005; elaboración propia. 
Figura 3. Deserción escolar en Ibagué, 1993 y 2005

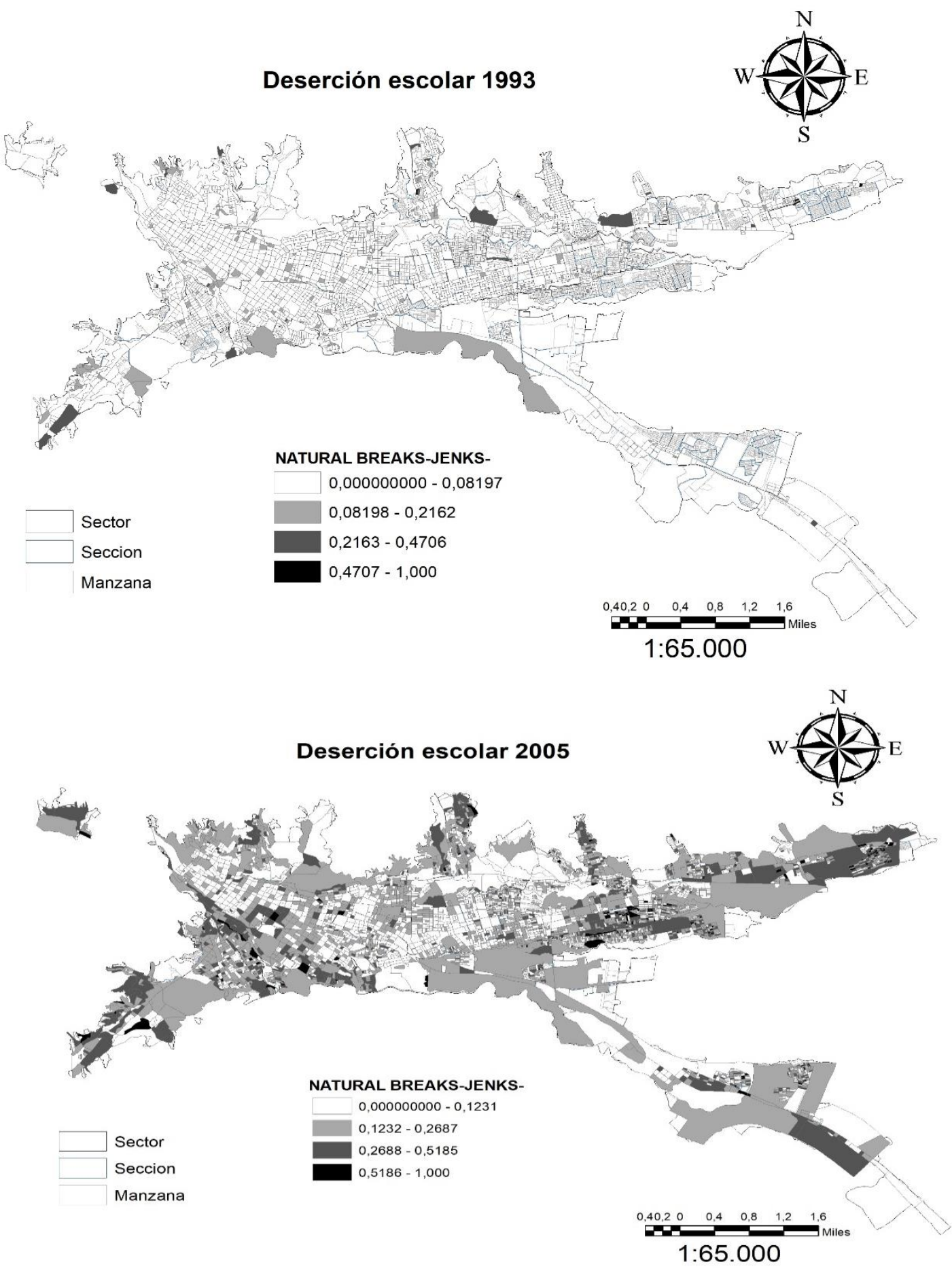

Fuente: Cartografia DANE, datos censales del DANE de 1993 y 2005; elaboración propia. 
El jefe de hogar desempleado -ver figura 4- y jefe de hogar con primaria completa -ver figura 5- también se encuentra en ambos años localizado en la comuna seis, con lo que difiere en las dos variables anteriores es que aparece la comuna siete como receptora de este grupo poblacional principalmente en el año 20005, la cual también es receptora de jefes de hogar sin nivel educativo para el año 2005 y no 1993, lo que podría explicarse porque la comuna siete ha sido receptora de población desplazada por la violencia, dentro de los problemas a su interior ha sido la deficiencia de la prestación de servicios públicos, estaba constituida por pocos barrios debido a que a la fecha de 1993 solo la conformaban 18 (Alcaldía de Ibagué, 2012c), su principal barrio era un corregimiento que se constituyó como barrio en los ochenta del siglo XX y para el POT del 2000 se proyectó la comuna siete como zona de expansión.

Figura 4. Jefe de hogar desempleado en Ibagué, 1993 y 2005

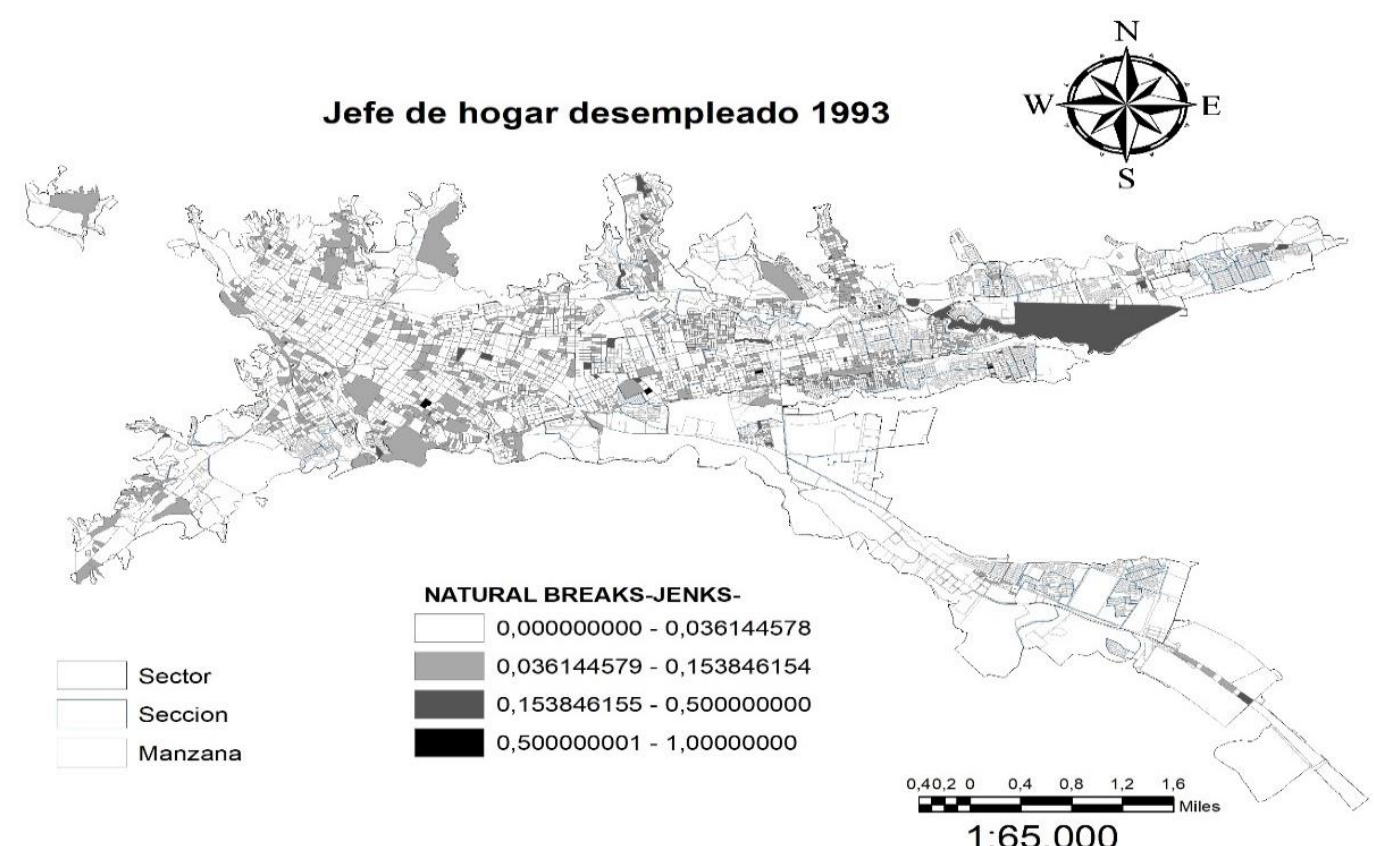

$1: 65.000$ 


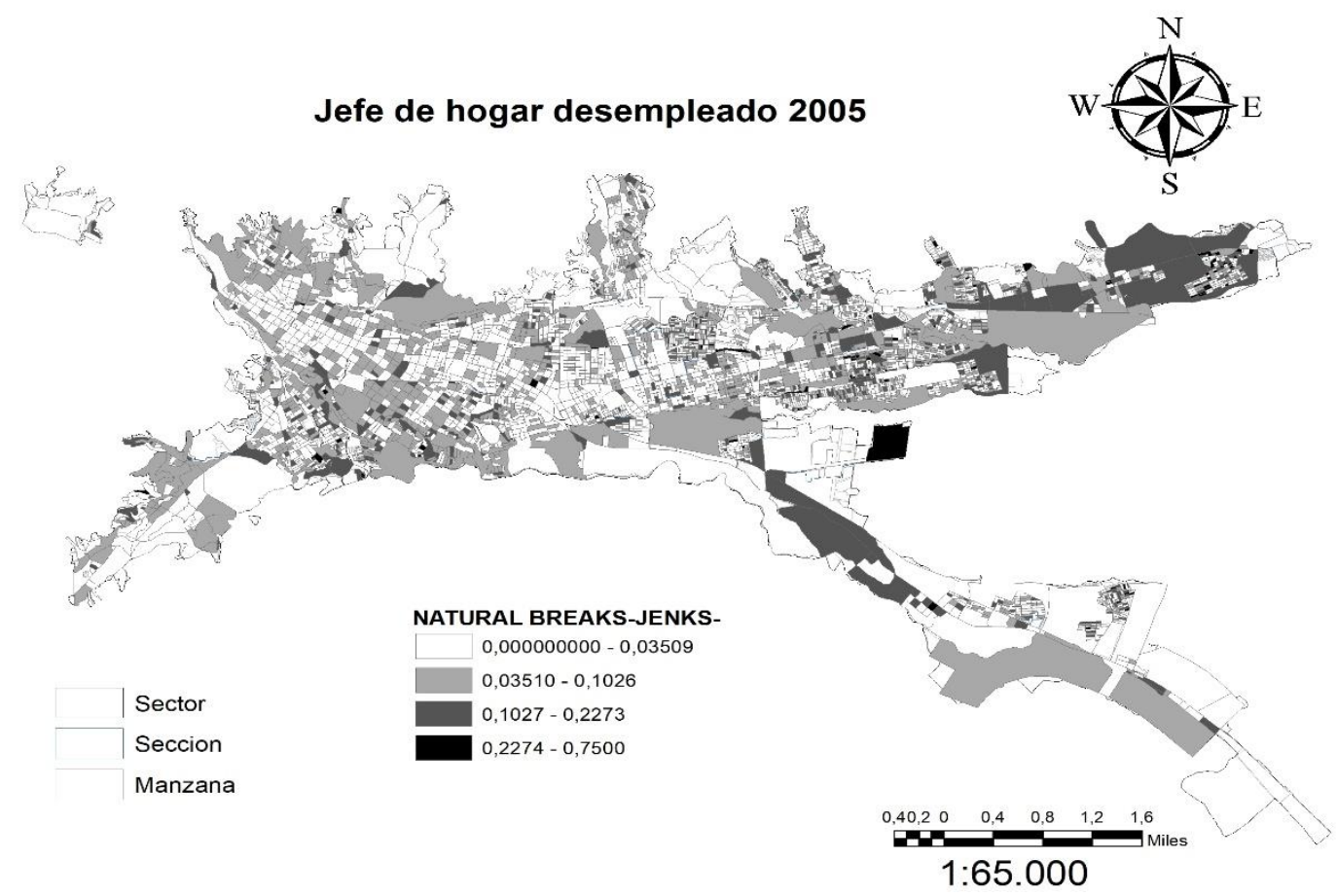

Fuente: Cartografía DANE, datos censales del DANE de 1993 y 2005; elaboración propia.

Figura 5. Jefe de hogar con primaria completa en Ibagué, 1993 y 2005

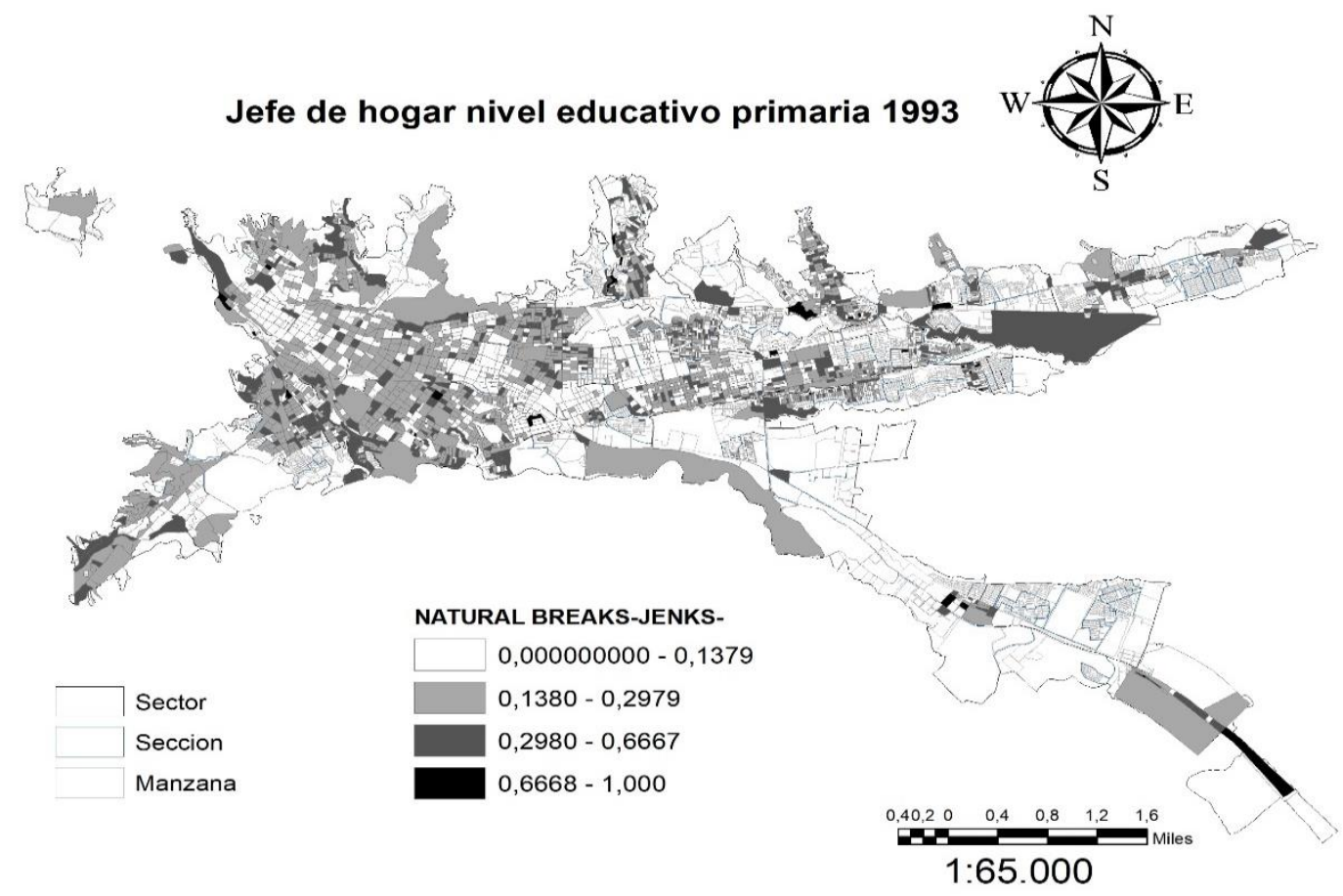




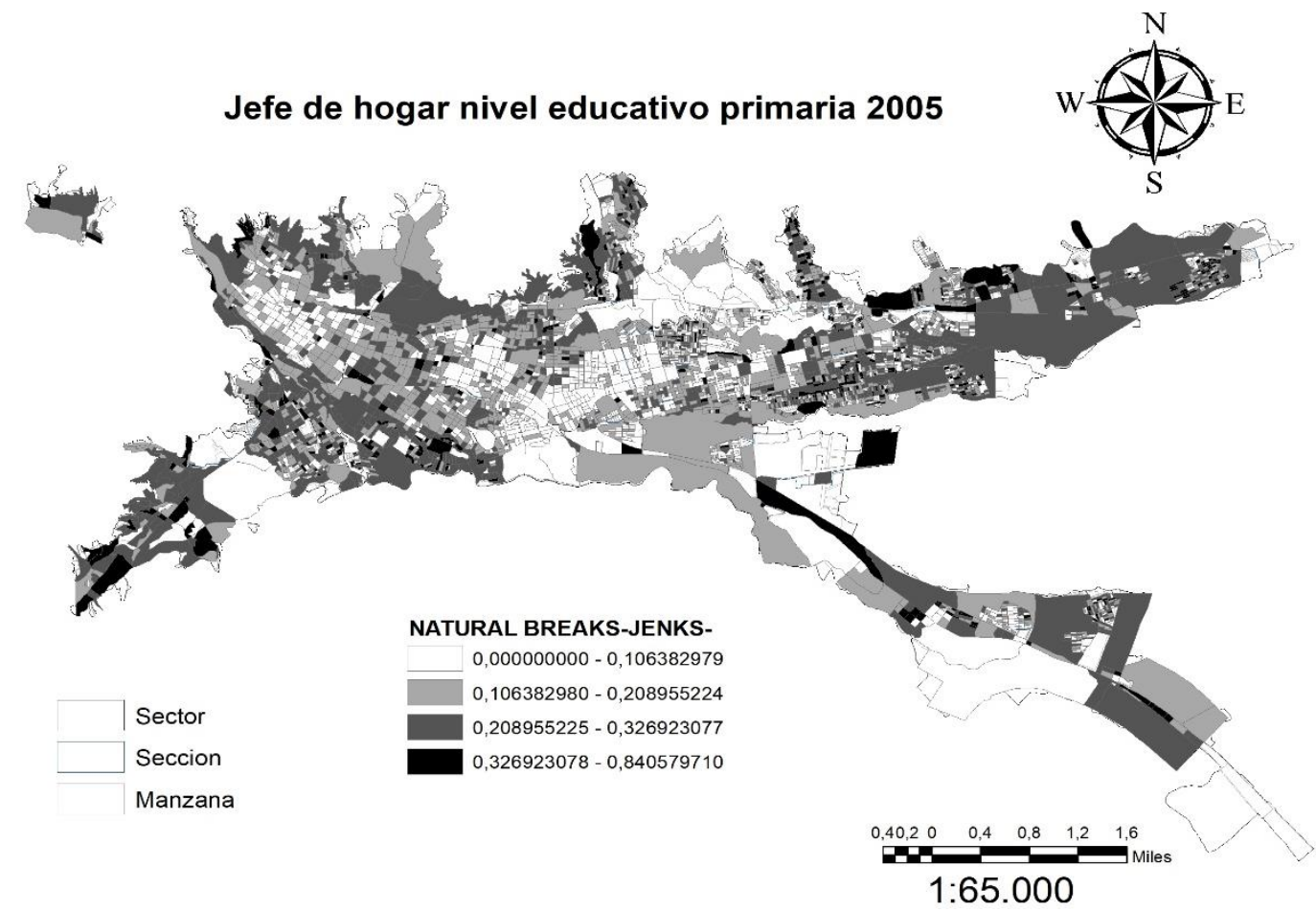

Fuente: Cartografía DANE, datos censales del DANE de 1993 y 2005; elaboración propia.

Los barrios como Modelia I y II, Santa Catalina I y II, Álamos, Nueva Bilbao, entre otros en el que hacen presencia características como los jefes de hogar con nivel educativo de primaria y sin nivel educativo -ver figura 2 y $5-$. Esta zona de la ciudad se ha considerado como zona de expansión en el que los desarrollos habitacionales están enfocados a suplir el déficit habitacional de hogares de ingresos bajos, en donde predomina la estratificación de los barrios en un 80\% entre el uno y dos (López, 2016) y poca planificación urbana.

Por su parte desde la dimensión habitacional y espacial las variables que más presenta escasez en la ciudad en especial en la comuna 13 son la falta de conexión a servicio de acueducto -ver figura $6-$ y de equipamientos culturales -ver figura $7-$ tanto para 1993 como para 2005.

La población ubicada en la comunas seis la compone población desplazada por la violencia, los cuales llegaron a conformar los barrios en mención no sólo para la mitad del siglo XX sino también a finales del mismo y comienzos del siglo XXI en donde estos barrios fueron los que más recibieron a esta población desplazada. Por su parte la 
población de los barrios como San Isidro, Jazmín y la Unión localizados en el extremo sur de la ciudad

Figura 6. Viviendas sin servicio de acueducto en Ibagué, 1993 y 2005

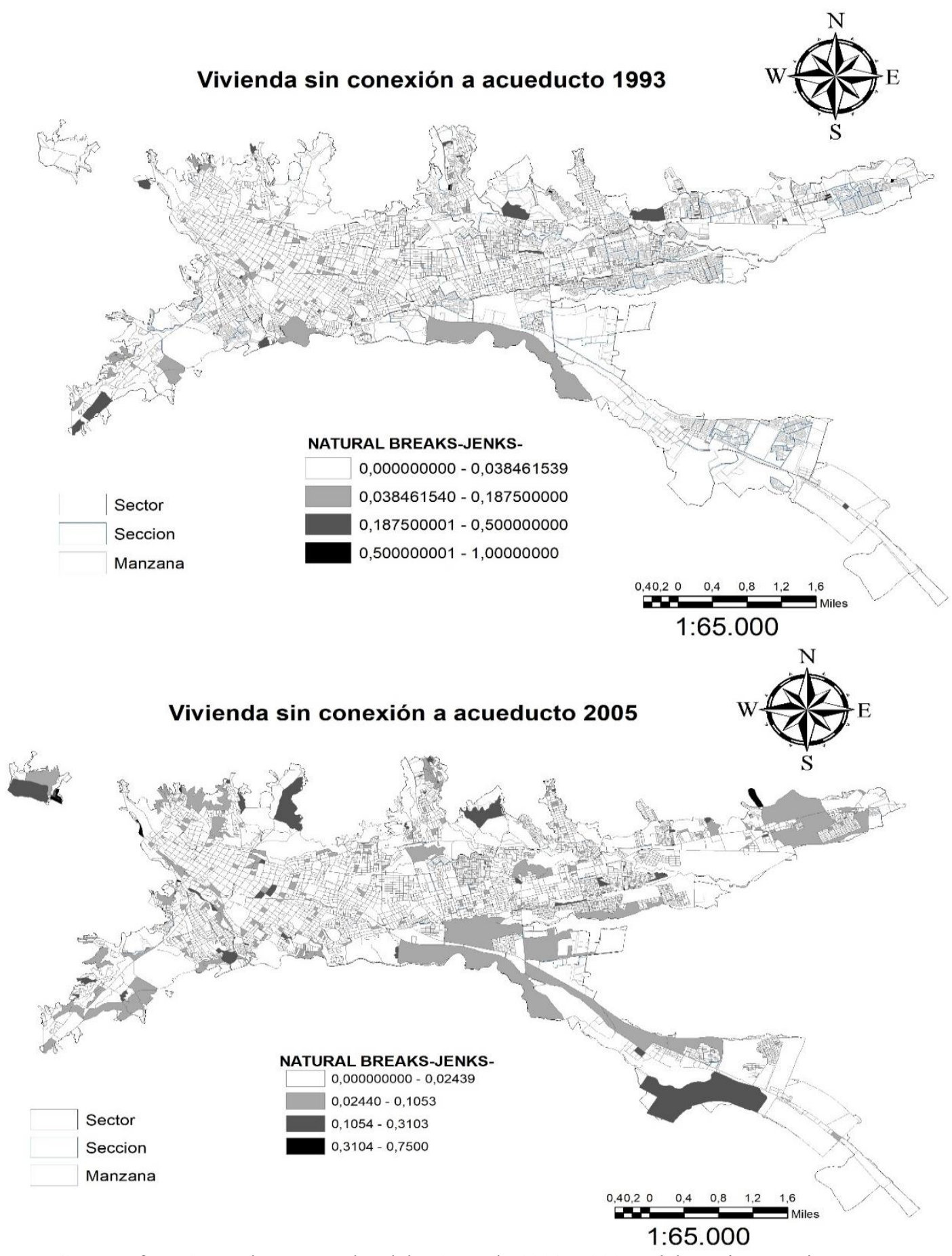

Fuente: Cartografia DANE, datos censales del DANE de 1993 y 2005; elaboración propia. 
Figura 7. Equipamiento cultural en Ibagué, 1993 y 2005
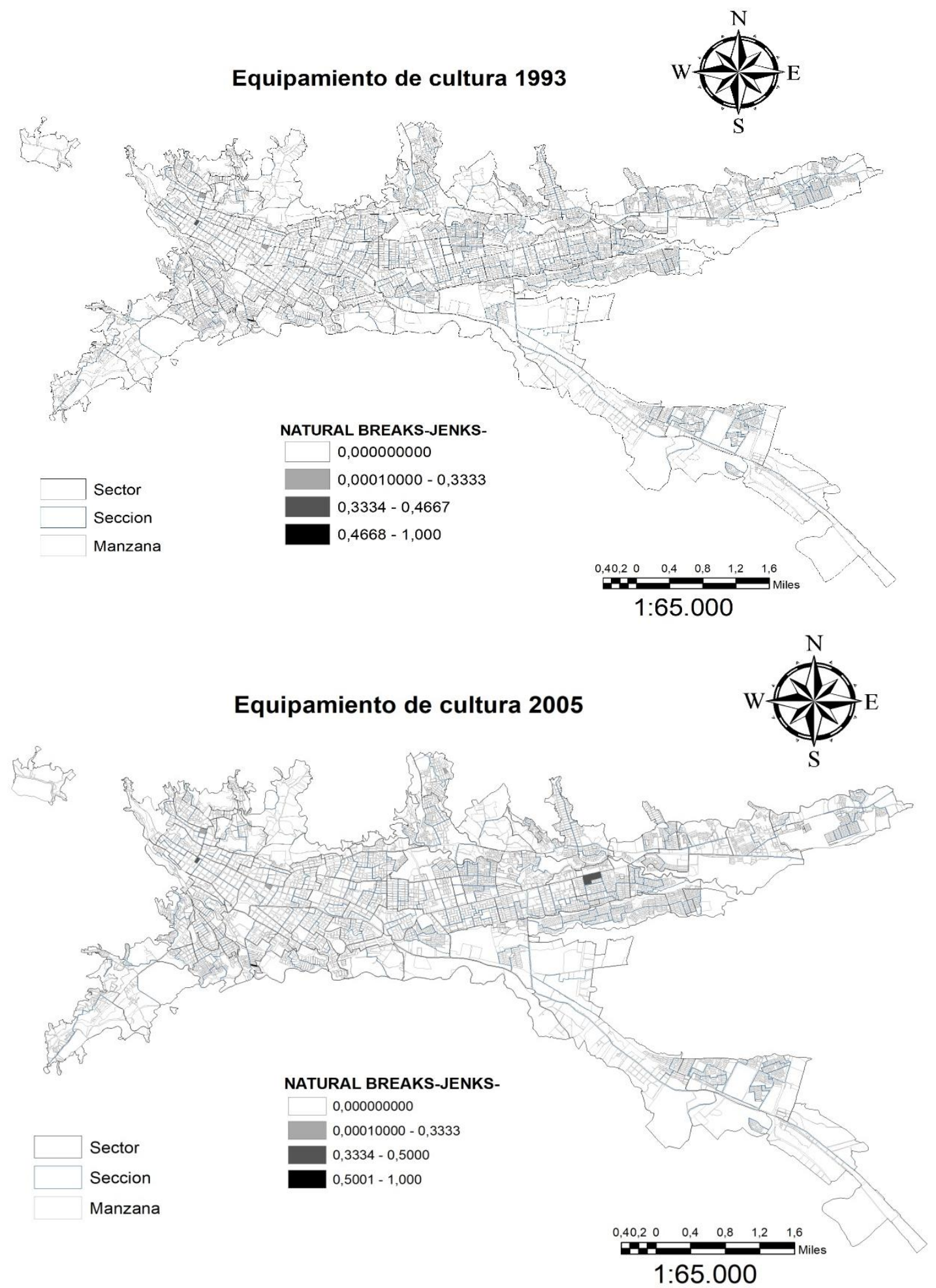

Fuente: Cartografía DANE, datos censales del DANE de 1993 y 2005; elaboración propia. 
pertenecientes a la comuna 13 además se caracterizarse por tener un mayor número de grupos poblacionales con problemas sociales, son barrios que fueron construidos sin previa planificación y que se ubican en son zonas con deficiente presencia de servicios públicos de acueducto, alcantarillado y energía; por lo que el abastecimiento de agua se hace a través de los siete acueductos comunitarios de la zona que no dependen de la Empresa Ibaguereña de Acueducto y Alcantarillado (IBAL) y que se abastecen principalmente del Río Chipalo. A su vez en estos barrios pertenecen a los estratos uno y dos (López, 2016), se ubican en zonas de riesgo por deslizamiento y apartados del centro de la ciudad (Alcaldía de Ibagué, 2012a).

Por otro lado, los jefes de hogar con secundaria completa - ver figura 8- y los jefes de hogar con postgrado completo -ver figura 9- se encuentran ubicados principalmente en las comunas uno, seis y nueve para los dos años de estudio; para el año de 2005 las comunas que predominan con jefe de hogar con posgrado completo son tres, cinco y seis y con nivel secundaria la comuna 12. No obstante para el caso de la comuna uno que en el año de 1993 predominaban los jefes de hogar con nivel educativo alto cuando cambiamos de periodo se observa que allí este grupo poblacional no es tan importante como antes, en la

Figura 8. Jefe de hogar con secundaria completa en Ibagué, 1993 y 2005

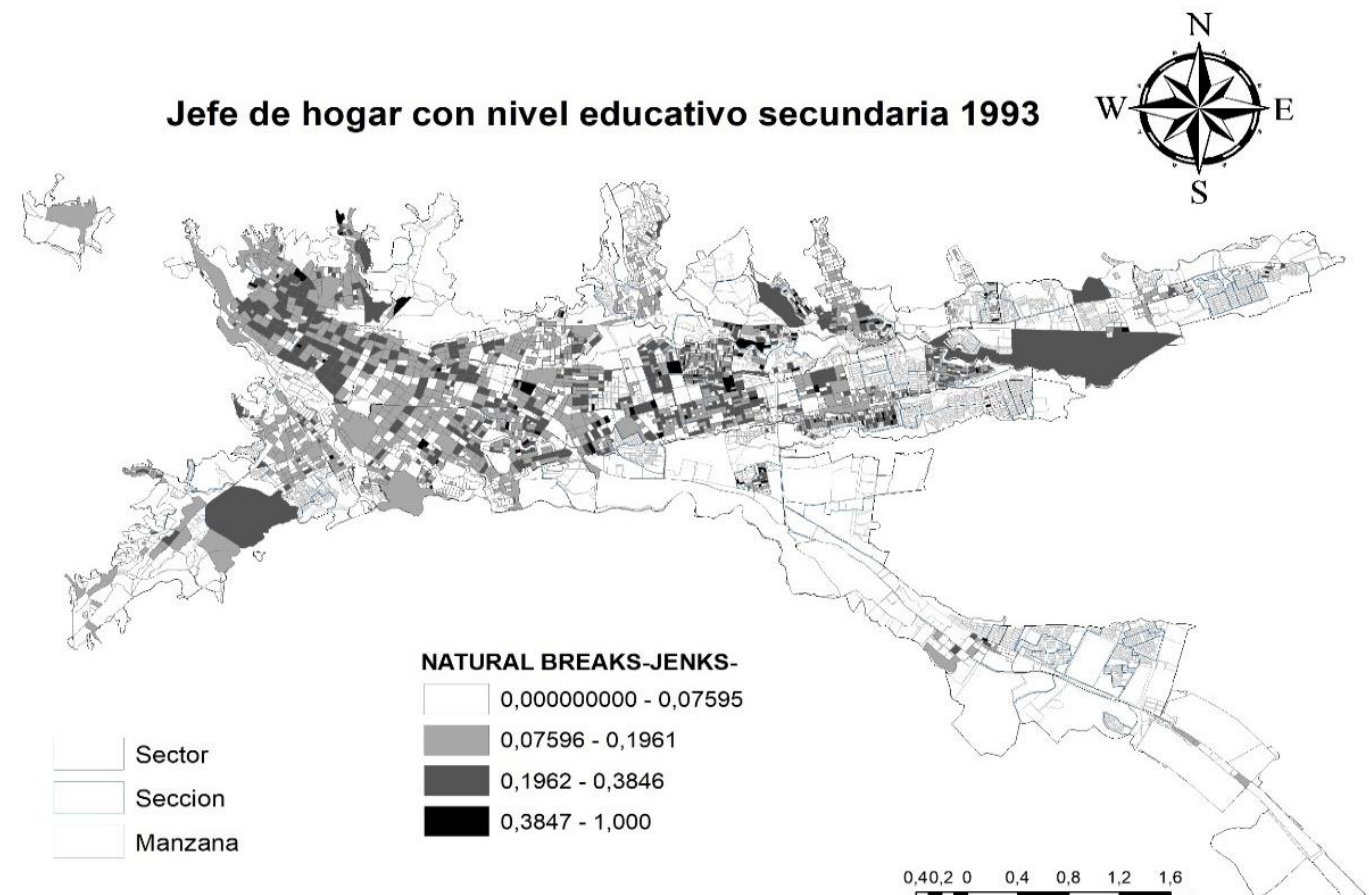

$1: 65.000$ 


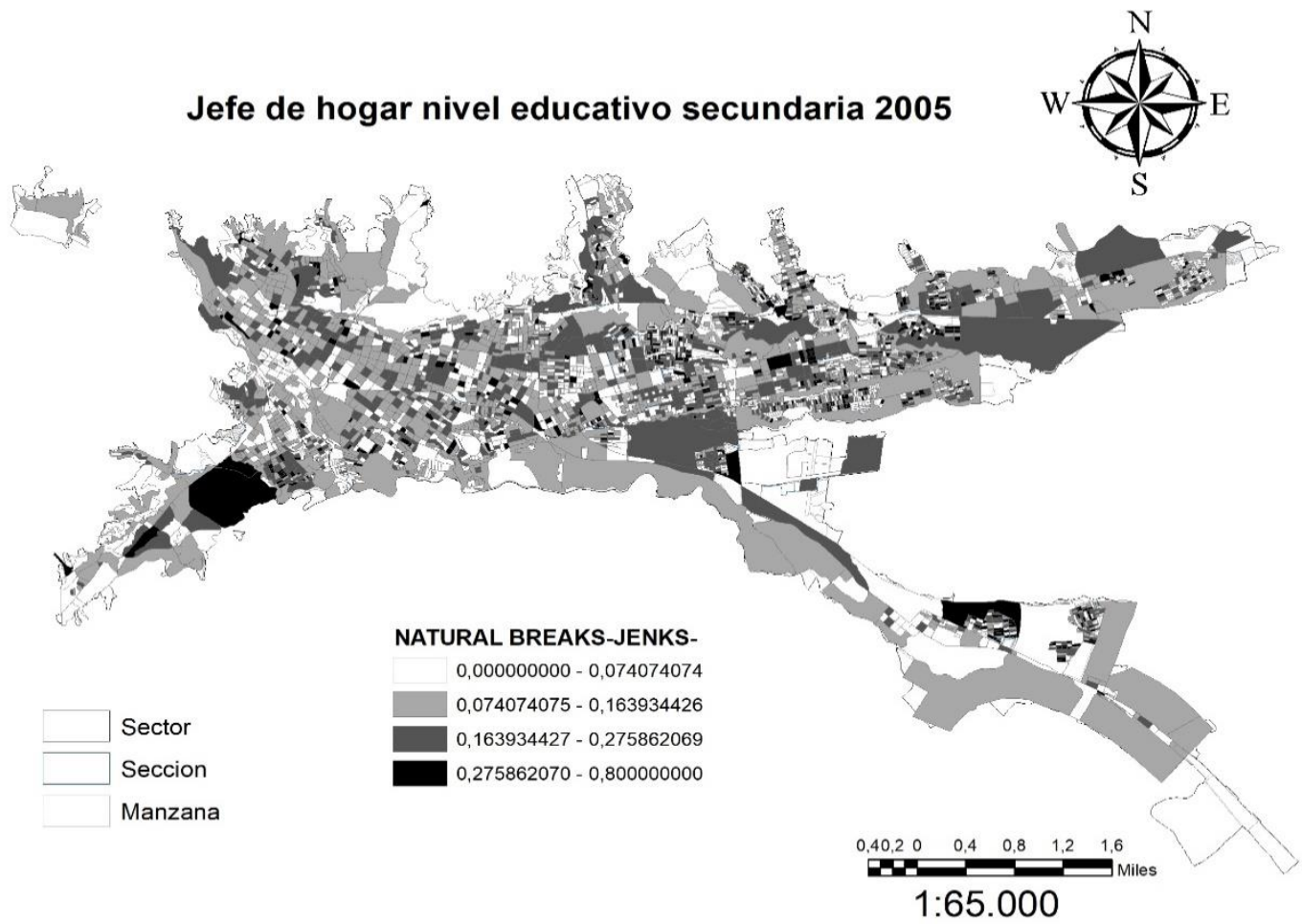

Fuente: Cartografia DANE, datos censales del DANE de 1993 y 2005; elaboración propia.

actualidad su estratificación predomina en un 60\% en el nivel medio bajo (López, 2016), para el año 2005 estos jefes de hogar localizados en inmediaciones de las comunas cinco y seis van conformando una franja que los va acercando y ya no se ven como dos zonas una arriba y otra abajo como en el año 1993. En cuanto a la dimensión habitacional las comunas que presentan menos déficit en los tres servicios aquí estudiados son la uno y la cinco.

Se evidencia que en donde se encuentran ubicados los jefes de hogar con nivel educativo superior completo la presencia de jefes de hogar desempleados son menores, al igual que la deserción escolar, de lo que se puede deducir es que esta relación inversa muestra que el nivel educativo es un determinante de la posición socioespacial de este grupo poblacional en la ciudad. Los barrios que se ubica en la comuna tres pertenecen cerca del $60 \%$ a los estratos medio y alto como Mi Botecito, Calambeo, Bosques de Calambeo y están en la zona noroccidental de la ciudad con grandes zonas verdes y cercanas al centro histórico de la misma. Por su parte en la comuna cinco ubicada en la zona nororiental de la ciudad colindando por el norte con la comuna 6 , cerca del $80 \%$ de sus barrios pertenecen a los 
estratos medio y alto destacándose los que se localizan entre la carrera quita y novena (conocida también como avenida guabinal) como por ejemplo El Conjunto Yacaira, Urbanización Parrales y sobre la Avenida Guabinal el Rincón de la Campiña, Urbanización Calatayud, Conjunto Cerrado la Ladera, entro otros.

Figura 9. Jefe de hogar con nivel educativo superior completo en Ibagué, 1993 y 2005

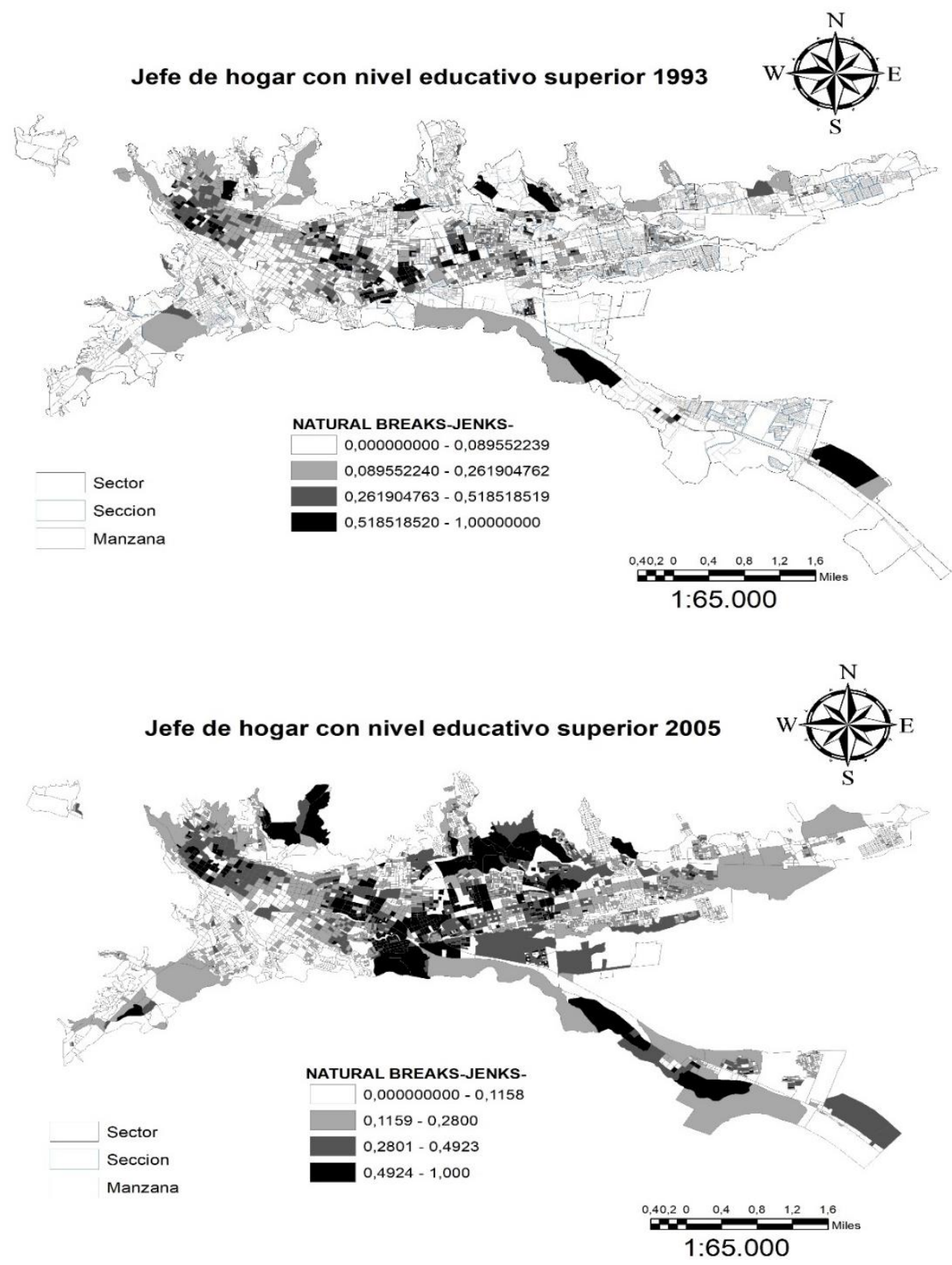

Fuente: Cartografía DANE, datos censales del DANE de 1993 y 2005; elaboración propia. 
Tanto la comuna seis y nueve contiene a todos los estratos sociales (Alcaldía de Ibagué, 2012d; López, 2016), sin embargo para la primera predominan los del uno al tres y los barrios de estos niveles de estratificación se ubican en la zona de ladera, los barrios de estratos altos por el contrario se ubican en la zona plana de ésta, además se encuentran más cerca de la avenida Ambalá (que conecta con el norte del Tolima), de la Universidad de Ibagué, de zonas accesibles y seguras (López, 2016) y cuenta con la mayor ocupación en hectáreas (68\%) de la comuna seis en la zona denominada el Vergel (Alcaldía de Ibagué, 2012b). Por su parte, la comuna nueve se caracteriza por tener zonas de enclave alrededor del Club Campestre; también se encuentran equipamientos como la Casa de la Moneda y la Cárcel, al ser la comuna con mayor extensión ha sido proyectada como zona de expansión en la que se han construido barrios tipo VIS como por ejemplo Villa Café y las Américas antes de la década de los noventa y después de este tiempo. A su vez esta comuna también se identifica por tener barrios de todos los estratos sociales, por ejemplo entre los barrios estrato medio y alto se encuentra Hacienda Piedra Pintada, Urbanización Portal del Campestre y Reservas del Campestre (estos dos últimos contiguo al Club Campestre).

Lo que se puede indicar para efectos comparativos entre los años censales y, principalmente, las variables por nivel educativo de los jefes de hogar, es que es posible inferir inicialmente una posible relación entre el mercado del suelo y la segregación residencial. Cuando se observa la localización de la población con bajo y alto nivel educativo entre un año y otro, se encuentra una localización generada por constructores bajo una subordinación de los precios del suelo (Sabatini, 2003). Así, los jefes de hogar con menor nivel educativo y desempleados se localizan a través del tiempo en las mismas zonas y presentan las mismas carencias; en esas mismas zonas también se proyectan y construyen proyectos inmobiliarios para la población de ingresos bajos en barrios de estratificación baja, por lo que el Estado, a través de sus programas habitacionales de VIP y VIS, los localiza allí con el fin de disminuir costos, a la vez que aglomeran pobres junto a otros pobres en terrenos baratos, con valores por metros cuadrados que oscilan entre $2.000 \mathrm{y}$ 65.000 pesos y que cuentan con estratificación baja (Secretaría de Planeación Municipal, 2014). 
En contraste, la localización de la población de alta renta se ha consolidado en terrenos con valores por metro cuadrado entre 109.000 y 163.000 aproximadamente, con estratificación media y alta. Esta población ya no se concentra en el centro tradicional de la ciudad y la zona del Vergel - en donde se han construido modernos conjuntos cerrados de apartamentos de estratificación alta—. Además, se ha consolidado la construcción de vivienda en altura en la zona geográfica central de la ciudad. Estas edificaciones están diseñadas para para brindar seguridad residencial, donde se construye un entorno homogeneizado sin lugar para grupos de personas diferentes a ellos (Cortés, 2010). De ahí que no se observa heterogeneidad de grupos sociales disímiles en una misma zona.

\subsection{Análisis de los factores de segregación residencial a través de indicadores} tradicionales

Los índices tradicionales de segregación permiten identificar que tan bien distribuidos están los grupos poblacionales en el espacio residencial y que tan cercanos pueden estar de grupos diferentes a ellos, lo que en términos de Francisco Sabatini son la concentración y homogeneidad social, respectivamente. El índice de segregación y de segregación ajustado por la contigüidad comparan la distribución espacial de los grupos a analizar con respecto al total poblacional, habitacional y espacial, su valoración está entre 0 y 1 , donde 0 es ausencia y 1 total segregación, resultado que al multiplicarse por 100 manifiesta la participación de cada grupo.

En la tabla cinco se muestran los resultados para todos los indicadores tradicionales, el IS e IS (Adj) se obtienen resultados similares en todas las variables y en ambos años. Para la dimensión socioeconómica en el año 1993 se encuentra que son los jefes de hogares desempleados y sin nivel educativo los que más se segregan, sin embargo para el 2005 los que más se segregan son los jefes de hogar sin nivel educativo y con nivel superior completo, para ambos años el grupo menos segregado son los jefes de hogar con educación primaria y secundaria completa. Estos resultados tienen correspondencia entre la distribución espacial de los jefes de hogar y su nivel de instrucción esto es que con este indicador se evidencia una ocupación diferencial en la ciudad. 
Tabla 5. Índices no espaciales de la segregación residencial por manzana en el municipio de Ibagué, 1993-2005

\begin{tabular}{|c|c|c|c|c|c|c|c|c|c|c|c|}
\hline \multirow{2}{*}{ DIMENSION } & \multirow{2}{*}{ VARIABLES } & \multicolumn{5}{|c|}{ ÍNDICES DE SEGREGACIÓN, 1993} & \multicolumn{5}{|c|}{ ÍNDICES DE SEGREGACIÓN, 2005} \\
\hline & & IS & IS(Adj) & $\mathbf{x P x}$ & Eta2 & DEL & IS & IS(Adj) & $\mathbf{x P x}$ & Eta2 & DEL \\
\hline \multirow{4}{*}{$\begin{array}{l}\text { Socio- } \\
\text { Económica }\end{array}$} & Jefe de Hogar con Primaria Completa & 0,1991 & 0,1937 & 0,0633 & 0,0128 & 0,9189 & 0,2225 & 0,215 & 0,0687 & 0,017 & 0,855 \\
\hline & Jefe de Hogar con Posgrado Completa & 0,4589 & 0,454 & $\mathbf{0 , 0 8 7 2}$ & 0,0555 & 0,9333 & 0,4194 & 0,4101 & 0,1156 & 0,064 & 0,867 \\
\hline & Jefe de Hogar sin Ningún Nivel Educativo & 0,4764 & 0,4742 & 0,03 & 0,0186 & 0,9454 & 0,4218 & 0,4183 & 0,0343 & 0,0206 & $\mathbf{0 , 8 8 5}$ \\
\hline & $\begin{array}{l}\text { Menores que no asisten a alguna institución } \\
\text { Educativa }\end{array}$ & 0,3376 & 0,3331 & 0,0566 & 0,0267 & 0,9208 & 0,3134 & 0,304 & 0,0861 & 0,0365 & 0,855 \\
\hline \multirow{3}{*}{ Habitacional } & $\begin{array}{l}\text { Vivienda sin conexión a la red de desagüe pública } \\
\text { (alcantarillado) }\end{array}$ & 0,6255 & 0,6168 & 0,2995 & 0,2564 & 0,9405 & 0,791 & 0,7844 & 0,2081 & 0,1956 & 0,908 \\
\hline & $\begin{array}{l}\text { Vivienda sin conexión a la red de agua corriente } \\
\text { pública (acueducto) }\end{array}$ & 0,8739 & 0,8716 & 0,1531 & 0,1469 & 0,9815 & 0,8042 & $\mathbf{0 , 8 0 0 7}$ & 0,1132 & 0,1054 & 0,923 \\
\hline & $\begin{array}{l}\text { Vivienda sin conexión a la red de electricidad } \\
\text { pública (Energía eléctrica) }\end{array}$ & 0,6267 & 0,6168 & 0,1882 & 0,1534 & 0,9573 & 0,7956 & 0,7911 & 0,1653 & 0,1573 & 0,928 \\
\hline \multirow{2}{*}{ Espacial } & Deporte & 0,6415 & 0,6414 & 0,6464 & 0,4914 & 0,996 & 0,6056 & 0,6055 & 0,6001 & 0,4436 & 0,993 \\
\hline & Cultura & \begin{tabular}{|l|}
0,9008 \\
\end{tabular} & 0,9008 & 0,4256 & 0,3924 & 0,9998 & 0,9258 & 0,9258 & 0,4306 & 0,4053 & 1 \\
\hline
\end{tabular}

Fuente: Elaboración propia, según datos censales del DANE de 1993 y 2005 
En contraste, se encuentran que los índices evidencian resultados diferentes para esta dimensión por escala de sector y sección porque en ambos años los jefes de hogar se segregan por nivel educativo alto y bajo y disminuye su nivel de un año (Ver Anexo 1 y 2), en cuanto las otras variables se presenta el mismo comportamiento de la escala manzana. Lo que se puede decir, es que hay concentraciones de los grupos poblacionales con alto índice de segregación en zonas de la ciudad (Sabatini, Wormald, Sierralta, \& Peters, 2008), lo cual tiene coherencia con la distribución socioespacial explicada en el análisis descriptivo, además que la dimensión socioeconómica se caracteriza por presentar segregación en aumento a una menor escala (Molinatti, 2013) y que tiende a disminuir de un año a otro. En cuanto a la dimensión habitacional y espacial se encuentra que las variables que más segregan por manzana son el servicio precario de acueducto y el equipamiento cultural para cada año, en donde la primera disminuye su nivel de un año a otro y la segunda no.

En relación al análisis de la segregación a una menor escala geográfica y su aumento de nivel, el resultado es relevante porque sin este ejercicio hubiera sido posible caer en el error de la limitación de los indicadores no espaciales de la segregación, como lo es el problema de la unidad espacial modificable (Garrocho \& Campos-Alanís, 2013; Sabatini \& Sierralta, 2006; Sabatini et al., 2008), no obstante se encontró un resultado esperado en el que "mayor el tamaño del área de medición, menor será el índice, acercándose a cero (...) y cuanto menor el área de medición, mayor el valor del índice, tendiendo al valor uno al acercarse al tamaño mínimo posible, el del hogar" (Sabatini et al., 2008, p. 25).

El índice de aislamiento $(x P x)$ indica la posibilidad de encuentro de un individuo con otro de su mismo grupo en una unidad espacial y el índice de aislamiento corregido $E t a^{2}$ lo que permite es ajustar por proporciones los diferentes grupos sobre el total de la población- ver tabla 5- lo que se evidencia es que la probabilidad de encuentro de la población con nivel socioeconómica baja está entre el 5\% y $8 \%$ y una probabilidad alta de aislamiento de los grupos diferentes a ellos, en el caso del grupo con nivel educativo alto se encuentra que entre el 6 y el 11\% es la probabilidad de encuentro entre la población igual que ellos por lo tanto la posibilidad de aislamiento con grupos diferente a ellos es alta para los años de estudio y en ambos casos, resultados que contrastan con lo que sucede en el 
contexto de las ciudades metropolitanas de Latinoamérica en las cuales los grupos de élite tienen un nivel alto de concentración y un nivel bajo de homogeneidad (Sabatini et al., 2008), en el caso de Ibagué se encuentra un nivel de segregación alto en las dos para el grupo de condición social alto, resultados que son coincidentes con la ciudad intermedia de Tunja (Giraldo, 2016).

En cuanto a las dimensiones habitacional y espacial se encuentra que la posibilidad de encuentro de los grupos poblacionales puede estar determinada por la deficiencia en el servicio de alcantarillado que está entre el 26\% y el 20\% para 1993 y 2005, respectivamente y el acceso a equipamientos colectivos como el de deporte para el caso de la dimensión espacial permitiría un encuentro entre el 50\% y 44\% para cada año y en ambos casos la probabilidad de encuentro disminuye. Lo que se deduce es que el grupo poblacional con condiciones socioeconómicas y habitacionales bajas se aísla mucho más de los grupos diferentes a ellos y que este mismo comportamiento sucede solo desde la dimensión socioeconómica para el grupo poblacional de estudio con nivel educativo alto, por lo tanto lo que se puede indicar es que existe una posible heterogeneidad de cada grupo social disímil. En relación a otras ciudades intermedias de Latinoamérica los resultados de Ibagué presentan el mismo comportamiento de ciudad como Córdoba y Tunja en Argentina y Colombia respectivamente (Giraldo, 2016; Molinatti, 2013).

Finalmente, los resultados del índice Delta (Del) indica que existe una alta concentración en todas las variables de estudio, no obstante el que este índice manifieste que los jefes de hogar sin nivel educativo, desempleado y jefes de hogar con nivel educativo superior completo hayan coincido en este resultado, no quiere decir precisamente que ambos grupos que son diferentes ocupen la misma cantidad de tierra, lo que podría pasar detrás de este resultado es que el primer grupo puede estar viviendo en espacios urbanos más pequeños, lo que significa que este tipo de grupo está localizado en zonas que por sus característica por ejemplo de riesgo, de inundación, de ladera, entre otros, no le sea posible habitarlos por más personas de la misma condición social (Monkkonen, 2012).

\subsection{Autocorrelación espacial de la segregación residencial}

A continuación se presentan los resultados es posible que estén sujetos a modificaciones debido a la dimensión espacial de los índices de autocorrelación debido a que se han hecho 
sugerencias sobre la matriz de pesos más óptima para llevar a cabo la ejecución de dichos índices, por lo se debe determinar los vecinos espaciales de cada observación, sin embargo se tiene en cuenta que "no existe una definición unánime para esta matriz y por el contrario se elige un criterio dependiendo de la naturaleza de análisis y por decisión del investigador" (Celis, 2010).

Los resultados de los indicadores espaciales van a determinar la tendencia de la distribución socioespacial de los grupos en estudio, el primer índice es el de Moran -ver tabla 6-, este índice mide el grado de proximidad entre las unidades territoriales en las que se localizan cada variable en estudio es decir, expresa si tienen un patrón aleatorio o no de la distribución de cada una de las categorías. Para todas las dimensiones en el año de 1993 el I de Morán indica que todas las variables arrojaron positiva y significativamente estadística lo que significa que si existe autocorrelación espacial, en todas sus dimensiones y se rechaza a hipótesis de aleatoriedad. Entonces, se puede decir que la probabilidad de que cada grupo poblacional se distribuya de manera aleatoria en la ciudad es baja. No obstante, para el año 2005 sólo la dimensión socioeconómica y habitacional fueron positivas y significativas, por lo tanto la dimensión espacial arroja que no hay correlación espacial, por lo tanto los resultados del índice de segregación y de Moran se corresponden en la dimensión socioeconómica porque en el año 2005 la población se segrega por condición social baja y alta y además se agrupa formando un clúster, estos resultados lo que muestran es que esta población no sólo está concentrada si no que internamente es homogénea y que sus composición social tiene relación con la de sus vecinos. Para el caso de la ciudad de Córdoba al igual que para Ibagué se encuentra que es el jefe de hogar según su nivel educativo superior es el que más se encuentra concentrado en el espacio, sin embargo, para la ciudad de Córdoba con el pasar de los años la concentración no aleatoria aumenta levemente en el caso de Ibagué es al contrario.

Tabla 6. Índices Espaciales de Correlación para un grupo por manzanas en el municipio de Ibagué, $1993-2005$.

\begin{tabular}{|l|l|l|l|}
\hline \multirow{3}{*}{ DIMENSION } & \multirow{2}{*}{ VARIABLES } & \multicolumn{2}{|c|}{$\begin{array}{c}\text { ÍNDICES ESPACIALES DE } \\
\text { CORRELACIÓN }\end{array}$} \\
\cline { 3 - 4 } & & I de Morán, 1993 & I de Morán, 2005 \\
\cline { 3 - 4 } & & Estadístico & Estadístico \\
\hline
\end{tabular}




\begin{tabular}{|c|c|c|c|}
\hline \multirow{6}{*}{ Socio-Económica } & $\begin{array}{l}\text { Jefe de Hogar con Primaria } \\
\text { Completa }\end{array}$ & 0,391 & 0,2422 \\
\hline & $\begin{array}{l}\text { Jefe de Hogar con Secundaria } \\
\text { Completa }\end{array}$ & 0,3557 & 0,1438 \\
\hline & $\begin{array}{l}\text { Jefe de Hogar con Posgrado } \\
\text { Completa }\end{array}$ & 0,4798 & 0,319 \\
\hline & $\begin{array}{l}\text { Jefe de Hogar sin Ningún } \\
\text { Nivel Educativo }\end{array}$ & 0,3342 & 0,2374 \\
\hline & Jefe de Hogar Desempleado & 0,0926 & 0,1209 \\
\hline & $\begin{array}{l}\text { Menores que no asisten a } \\
\text { alguna institución Educativa }\end{array}$ & 0,3664 & 0,2304 \\
\hline \multirow{3}{*}{ Habitacional } & $\begin{array}{l}\text { Vivienda con o sin conexión } \\
\text { a la red de desagüe pública } \\
\text { (alcantarillado) }\end{array}$ & 0,2068 & 0,0924 \\
\hline & $\begin{array}{l}\text { Vivienda con o sin conexión } \\
\text { a la red de agua corriente } \\
\text { pública (acueducto) }\end{array}$ & 0,0777 & 0,08 \\
\hline & $\begin{array}{l}\text { Vivienda con o sin conexión } \\
\text { a la red de electricidad } \\
\text { pública (Energía eléctrica) }\end{array}$ & 0,2065 & 0,0507 \\
\hline \multirow{4}{*}{ Espacial } & Salud & 0,0034 & $-0,0057$ \\
\hline & Educación & 0,0009 & $-0,0142$ \\
\hline & Deporte & 0,1821 & $-0,0141$ \\
\hline & Cultura & 0,0031 & $-0,009$ \\
\hline
\end{tabular}

Fuente: Elaboración propia, según datos censales del DANE de 1993 y 2005

Por su parte el índice LISA identifica los patrones espaciales locales, el cual a través de un mapa dividido en cinco colores mostrará la existencia de clusters altos de la variable de análisis es decir, si el valor de la categoría es alto y el valor de la entidad vecina, del mismo modo muestra este mismo comportamiento si el valor de la categoría es bajo al igual que la entidad vecina -High-high y low-low, respectivamente-, otro posible resultado es que la unidad censal con valores bajos acompañada de valores altos y viceversa -Lowhigh y High-low, respectivamente- y donde no hay significancia estadística (Celis, 2010; L. Fuentes, 2012). 
Figura 10. Índices Espaciales de Correlación local del jefe de hogar por nivel educativol por manzanas en el municipio de Ibagué, 1993 - 2005.

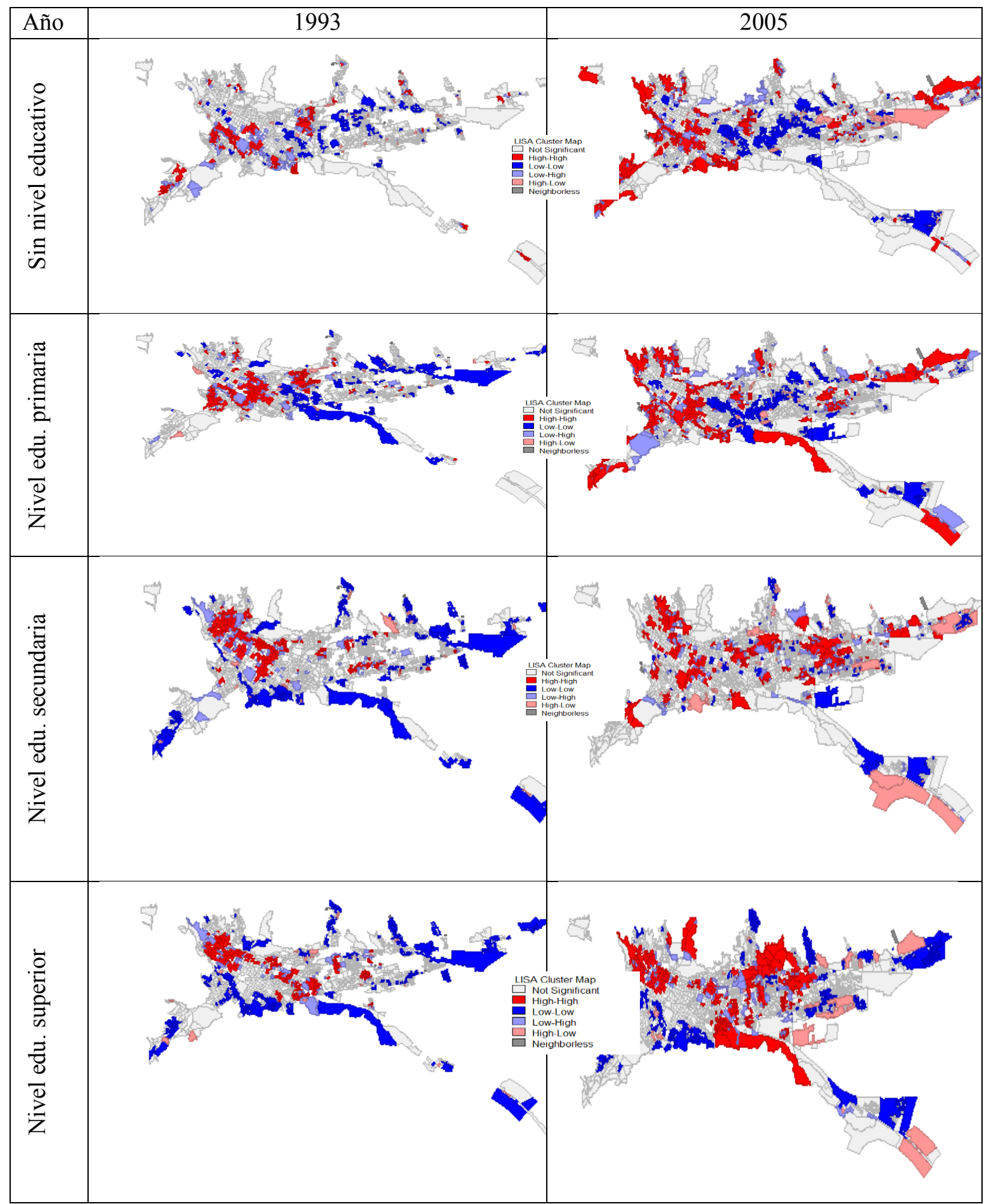

Fuente: Elaboración propia, según datos censales del DANE de 1993 y 2005 
Los resultados del I de LISA para el grupo de jefes de hogar medidos por su nivel instrucción se encuentra un patrón general positivo de asociación espacial de color rojo -ver figura 10 - esto es, para los años 1993 y 2005 los jefes de hogar con nivel educativo superior alto se evidencia una presencia significativa de este grupo con vecinos que tienen sus mismas característica, a su vez se encuentra que el cono de alta renta que es característico del patrón tradicional de segregación ya no se presenta en el año 2005 como si estaba para el año 1993.

En cuanto a los jefes de hogar con primaria y con secundaria completa presentan clusterización en 1993 y para el año 2005 este comportamiento ya no es el mismo ya que estos mismos grupos se encuentran más dispersos por toda la ciudad, sin embargo los jefes de hogar con primaria completa para el año de 1993 presenta un clúster azul con correlación negativa en donde es poco probable que se vayan a localizar en esas zonas con baja presencia de jefes con su mismo nivel educativo, patrón que cambia en el año 2005.

Por otro lado, a través del tiempo se observa como el grupo sin nivel educativo se va agrupando localmente por manzanas al igual que el grupo con secundario completo. A su vez se encuentra que para la ciudad de Córdoba hay aglomeración local importante de población con riqueza, en lo que difiere con el caso de estudio de Ibagué es en las zonas donde se ubican mientras que en Córdoba están en el centro y el noroeste de la ciudad en Ibagué, se les encuentra principalmente en el norte, nororiente y suroriente de ella.

Para el caso de la deserción escolar como los jefes de hogar desempleados no se encuentran segregados localmente para el año 1993 como si para el año 2005 -ver figura 11-, en ambos grupos se encuentra que la espacialización es similar en la zona de expansión de la comuna 7 al noroccidente de la ciudad por lo tanto hay un patrón de localización similar entre estas dos variables, sin embargo la deserción de menores de 16 años se localiza además del extremo nororiente también en el suroccidente de la ciudad. Por su parte los desempleados presentan aglomeración en la comuna 11 y parte de la comuna 13 al extremo suroccidente y en la comuna 8 , las cuales tienen en común la estratificación socioeconómica baja. 
Figura 11. Índices Espaciales de Correlación local de deserción escolar y jefe de hogar desempleado por manzanas en el municipio de Ibagué, 1993 - 2005.

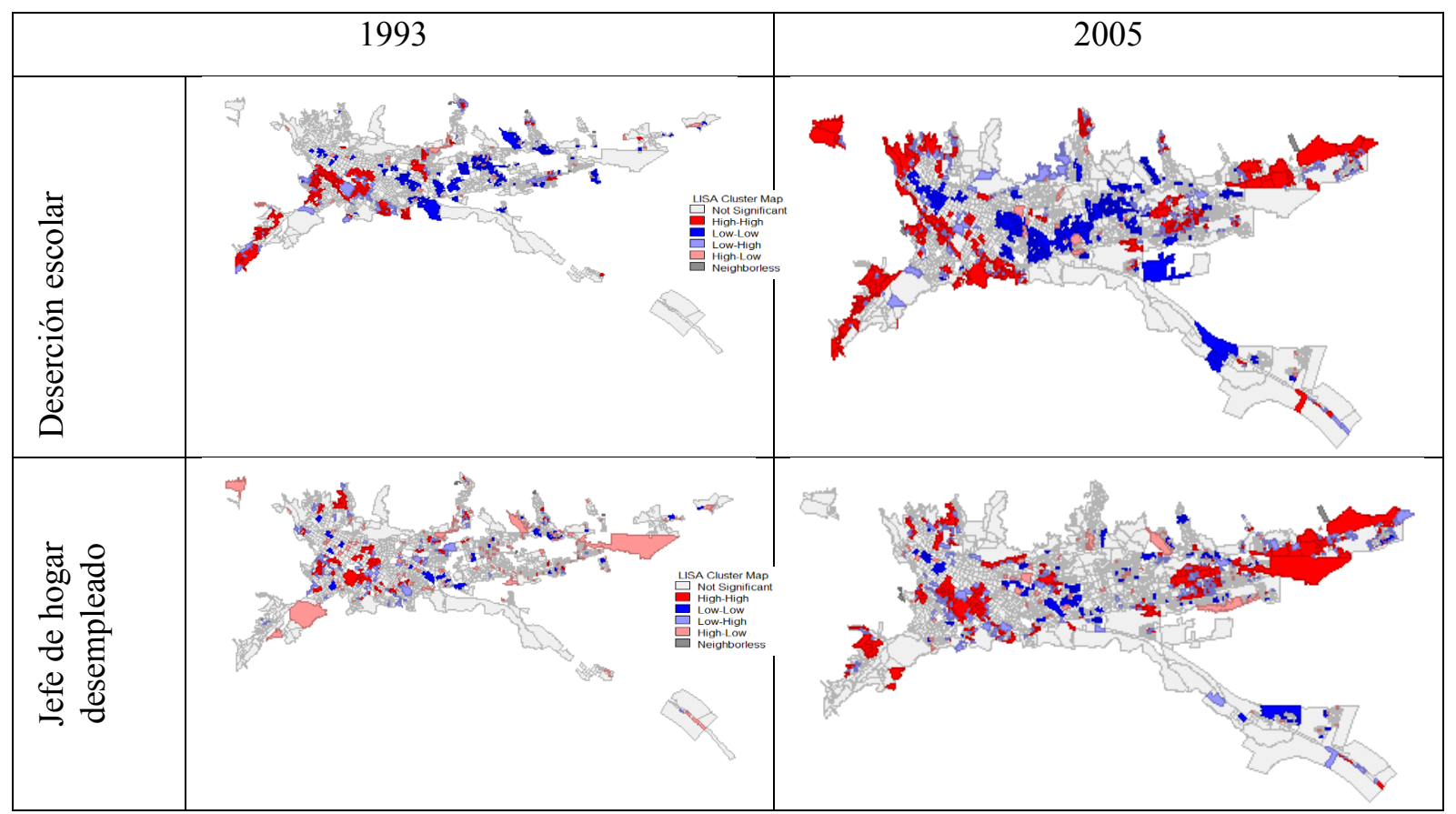

Fuente: Elaboración propia, según datos censales del DANE de 1993 y 2005

Por otro lado, las condiciones deficientes de los servicios públicos indica que el patrón de agrupación espacial sobre sale para el año 2005 -ver figura 12-, en todos los servicios que para el año 1993 donde se observa una dispersión de estos, es relevante indicar que la localización de estos servicios deficientes están principalmente en las zonas periféricas de la ciudad. Por último, los resultados de la dimensión espacial del índice local se corresponden con los del índice global para el año del 2005 en donde hay localización aleatoria de acuerdo al índice de Moran y para el índice de LISA no se encuentra aglomeración entre vecinos con características iguales. 
Figura 12. Índices Espaciales de Correlación local de la vivienda sin servicios públicos】 por manzanas en el municipio de Ibagué, 1993 - 2005.

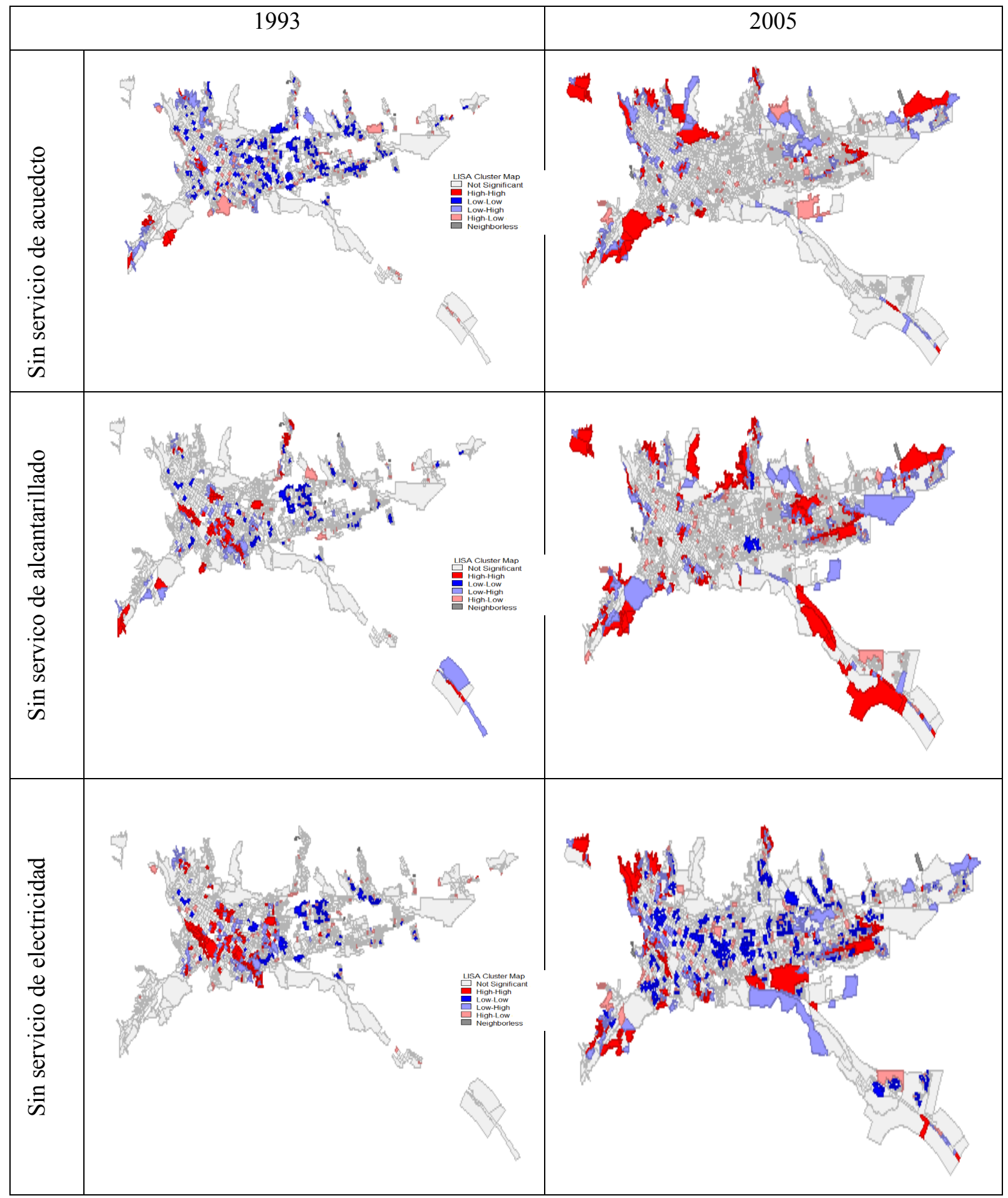

Fuente: Elaboración propia, según datos censales del DANE de 1993 y 2005 


\section{Conclusiones}

Se encuentra que bajo la dinámica de la entrada en vigor del neoliberalismo a partir de la década de los noventa del siglo XX, en la ciudad de Ibagué se presenta una nueva expresión de la segregación residencial a partir de la irrupción de nuevos desarrollos inmobiliarios tanto para residencia como para locales comerciales (Ávila, 2003), esto se explica cuando

el capital, (...), aparece como organizador y estructurador territorial preponderante, basándose en los múltiples recursos y ventajas competitivas de cada porción del territorio metropolitano, extrayendo las plusvalías más cuantiosas precisamente de las singularidades y especificidades que hacen de cada fragmento el lugar óptimo para cada tipo de producción (Ciccolella \& Vecslir, 2010, p. 2)

De esta manera, se puede decir que la estructura monocéntrica de anillos del modelo tradicional de la segregación residencial cambia a una de multicentrismos expresando así una nueva estructura de la segregación, cambio en el que jugó un papel importante la escala geográfica en la que se estudia el fenómeno debido a que la fragmentación de los barrios ha contribuido a pequeña escala a que la segregación sea más fina, manifestando que no hay una heterogeneidad real de los grupos poblacionales disimiles, al contrario se estaría presentando una aparente cercanía física más no social de estos grupos poblacionales.

Si bien es cierto es una dinámica que ha sido estudiada y la teoría se ha desarrollado a partir de estudios de caso de ciudades metropolitanas, la ciudad de Ibagué como ciudad intermedia no escapó a esta dinámica aunque su expresión se manifestó de manera tardía, en cuanto al tiempo se refiere.

De ahí que el cambio del patrón tradicional de la segregación a su nueva expresión se haya evidenciado con la disminución en la homogeneidad de los grupos poblaciones de menores niveles educativos en análisis tanto cartográfico como con los índices tradicionales de la segregación -índice de segregación ajustado por la contigüidad y el índice de segregación-, análisis que permitió poner en manifiesto cómo para 1993 la población de los jefes de hogar se segregaba más por niveles educativos bajos, en cambio cuando se analiza en 2005 estos mismos índices, se encuentra que la segregación ya no se da solo desde los niveles bajos de educación de los jefes del hogar sino también de los que tienen niveles de 
instrucción superior completo, por lo que se da segregación residencial en una doble vía segregación forzada y voluntaria, respectivamente.

Además se encuentra que este es un fenómeno que se refuerza a partir de los agentes como el Estado y el mercado, los cuales contribuyen a que la posición social ya no se determine a través de la posición geográfica - distancia- ya que se desarrollaron nuevas lógicas de separación y fronteras urbanas, en el que las ciudades pasan de ser ortogonales a tener un modelo fractal.

Por lo tanto, la nueva expresión de la segregación residencial debe ser tenida en cuenta para la elaboración de las políticas públicas que están encaminadas a integrar los territorios y no a separarlos más de lo que ya están, por lo que la planificación de los barrios debe de estar enfocada a reconocer a todos los grupos sociales sin distinción de clases y que en las políticas diseñadas se tenga en cuenta a la población que pretende ayudar ya que, sin esto no es posible que tenga efectos a largo plazo en sus comunidades.

Evidencia de esto es la constatación de un cambio en el patrón de segregación residencial de uno tradicional a uno nuevo, es un resultado relevante que manifiesta cuáles han sido las falencias que se han dado en el diseño de la política urbana de una ciudad intermedia como Ibagué, que en lugar de contribuir a la integración socioespacial, lo que ha sucedido es que ya no solo se segregan los grupos poblacionales de clase baja, sino además los de clase alta. Otro resultado relevante a tener en cuenta, es la existencia de barrios socialmente mixtos en una ciudad segregada, lo que muestra que esta política de integración que tradicionalmente fue implementada y que actualmente se utiliza en contextos neoliberales (Ruiz-Tagle, 2016), es evidencia que no es una estrategia suficiente para la socialización diversa entre grupos disímiles, de ahí que es menester que los encuentros entre esos grupos sea de calidad es decir, equitativos y no casuales, en donde la cercanía no solo se dé por una disminución en la distancia física sino además en la social (Saraví, 2008).

Al mismo tiempo, encontrar que los grupos con nivel socioeconómico alto tienen una probabilidad de encuentro más alta entre ellos que con grupos diferentes a estos, es un llamado de atención para que las instituciones transformen la estrategia de invertir en espacio público e infraestructura, esto con el fin de garantizar igualdad en la distribución de los equipamientos colectivos, debido a que lo que se ha evidenciado es que esas obras 
terminan por aumentar el valor del suelo urbano en el que habitan los grupos sociales con ingresos altos (González, 2006).

En este sentido, los interrogantes que siguen de este trabajo y que se desarrollan en la tesis doctoral que me encuentro realizando son: ¿Ha sido la fragmentación urbana la que ha contribuido al cambio de la expresión de la segregación residencial en las ciudades metropolitanas e intermedias de Latinoamérica?, ¿En qué medida las nuevas centralidades en lugar de acentuar, pueden contribuir a la mitigación de la segregación residencial?, ¿Existe cohesión social en aquellas zonas donde existe una aparente mezcla entre grupos socioeconómicos disimiles entre sí, salvaguardando la diferencia de ingresos y de las posiciones laborales?.

\section{BIBLIOGRAFÍA}

Ábramo, P. (2003). La teoría económica de la favela: cuatro notas sobre la localización residencial de los pobres y el mercado inmobiliario informal. Ciudad y Territorio: Estudios Territoriales, XXXV, 273-294.

Aguilar, A. G., \& Mateos, P. (2011). Diferenciación sociodemográfica del espacio urbano de la ciudad de México. Eure, 37(110), 5-30.

Alcaldía de Ibagué. (2008). Estudio de caracterización e identificación de asentamientos humanos precarios en la ciudad de Ibagué. Ibagué.

Alcaldía de Ibagué. (2012a). Plan de Desarrollo Socioeconómico y Territorial : Comuna 13, 2012-2015. Ibagué.

Alcaldía de Ibagué. (2012b). Plan de Desarrollo Socioeconómico y Territorial : Comuna 6, 2012-2015. Ibagué.

Alcaldía de Ibagué. (2012c). Plan de Desarrollo Socioeconómico y Territorial : Comuna 7 , 2012-2015. Ibagué.

Alcaldía de Ibagué. (2012d). Plan de Desarrollo Socioeconómico y Territorial : Comuna 9, 2012-2015. Ibagué.

Alessandri, A. F. (2013). A Prática Espacial Urbana Como Segregação e o "Direito à Cidade" Como Horizonte Utópico. In A CIDADE CONTEMPORÂNEA SEGREGAÇÃO ESPACIAL (pp. 96-110). Sao Pulo: Contexto.

Aliaga, L., \& Álvarez, M. J. (2010). Segregación Residencial en Bogotá a través del Tiempo y diferentes escalas. Lincoln Institute of Land Policy.

Apparicio, P., Fournier , É., \& Apparicio, D. (2013). Geo-Segregation Analyzer: a multiplaform application (version 1.1). Montreal: Spatial Analysis and Regional Economics Laboratory (SAREL), INRS Urbanisation Culture Société

Arriagada, C., \& Rodríguez, J. (2004). Segregación residencial en la ciudad latinoamericana, $X X I X, 5-24$.

Ávila, J. (2003). Globalización y nuevas cartografías de la segregación urbana en Lima metropolitana. Debates En Sociología, 53-76.

Bäbr, J., \& Borsdorf, A. (2005). La Ciudad Latinoamericana: La construcción de un modelo. Vigencia y perspectivas. Revista de Ciudad, Urbanismo y Paisaje Ur[b]Es, 
$207-221$.

Buzai, G. (2003). Mapas Urbanos Sociales. Buenos Aires: Lugar Editorial.

Castells, M. (2008). La Cuestión Urbana. México: Siglo Veintiuno Editores, S.A.

Celis, M. (2010). ¿Está segregada la pobreza en Manizales? RegionEs, 5, 48-87.

CEPAL. (2017). Panorama Social de América Latina. Cepal.

Ciccolella, P., \& Vecslir, L. (2010). Nuevos espacios del terciario y transformación metropolitana en Buenos Aires. In XI Seminario Internacional RII y IV Taller de Editores RIER Universidad Nacional de Cuyo, 26-30 de octubre de 2010 Grupo (pp. 26-30). Universidad Nacional de Cuyo, 26-30 de octubre de 2010.

Clavijo, C. (2009). Crecimiento Urbano y Ordenamiento Territorial en Ibagué 1997- 2007 Cuatro Casos de la Provisión de Vivienda Nueva 1) El Vergel, 2) Los Tunjos, 3) Vasconia y Nueva Castilla y 4) El Oasis y San Gelato. Universidad Nacional de Colombia. https://doi.org/10.1017/CBO9781107415324.004

Corrêa, R. L. (1989). O Espaço Urbano. São Paulo: Ática S.A.

De Mattos, C. (2002). Santiago de Chile de cara a la Globalización: ¿otra ciudad? Revista de Sociologia e Politica, 19, 31-54. https://doi.org/http://dx.doi.org/10.5380/rsp.v19i0

Feitosa, F. da F. (2005). Índices Espaciais Para Mensurar a Segregação Residencial: $O$ Caso de São José Dos Campos (sp). Instituto Nacional de Pesquisas Espaciais. INPE.

Fernández de Córdova, G. (2012). Nuevos patrones de segregación socio-espacial en Lima y Callao 1990-2007. Nuevos desafíos para la metrópoli. Cuadernos de arquiectura y ciudad. Lima.

Fuentes, C., \& Hernández, V. (2013). Segregación socioespacial y accesibilidad al empleo en Ciudad Juárez, Chihuahua (2000-2004). Región y Sociedad, 56, 44-69.

Fuentes, L. (2012). Ciudades y sociedades urbanas en transformación. Competitividad, reestructuración y cohesión social en Bogotá, Lima y Santiago en las últimas décadas. Pontificia Universidad Católica de Chile.

García de la Rosa, J. (2011). Análisis exploratorio de datos espaciales de la segregación urbana en Ciudad Juárez. Economía, Población y Desarrollo, 27-37.

Garrocho, C., \& Campos-Alanís, J. (2013). Réquiem por los indicadores no espaciales de segregación residencial. Papeles de Poblacion, 19(77), 269-300.

Giraldo, C. (2016). Patrón de segregacion residencial en Tunja 2005 : Aproximación desde las tecnologías de información geográfica y la estadística espacial. Cuadernos Geográfico, 55, 195-216.

González, J. (2006). De la ciudad al territorio. La configuración del espacio urbano en Ibagué 1886-1986. Ibagué: Aquelarre. Centro Cultural Universidad del Tolima.

Groisman, F., \& Suárez, A. L. (2006). Segregación residencial en la Ciudad de Buenos Aires. Población de Buenos Aires, 3(4), 27-37.

Harvey, D. (1977). Urbanismo y Desigualdad Social (1st ed.). Madrid: Siglo Veintiuno Editores, S.A.

Janoschka, M. (2002). El nuevo modelo de la ciudad Latinoamericana: Fragmentación y privatiación. EURE, XXVIII, 11-29. https://doi.org/http://dx.doi.org/10.4067/S025071612002008500002

Jargowsky, P. (1996). Take the Money and Run: Economic Segregation in U.S Metropolitan Areas.

Johnston, R., Poulsen, M., \& Forrest, J. (2007). Ethnic and Racial Segregation in U.S. Metropolitan Areas, 1980-2000: The Dimensions of Segregation Revisited. Urban 
Affairs Review, 42(4), 479-504. Retrieved from http://uar.sagepub.com/cgi/content/abstract/42/4/479

Kaztman, R. (2003). La dimensión espacial en las políticas de superación de la pobreza urbana. Serie Medio Ambiente y Desarrollo (Vol. 59). Santiago de Chile.

Lan, D., \& Linares, S. (2007). Analisis Multidimensional De La Segregación Socioespacial en Tandil (Argentina) Aplicando SIG. Investigaciones Geográficas, 44, 149-166.

Lefebvre, H. (1976). Espacio y Política. El Derecho a la Ciudad II. Barcelona: Ediciones Península.

Lefebvre, H. (1978a). De lo Rural a lo Urbano. Barcelona: Ediciones Península. https://doi.org/10.1177/072551369203300110

Lefebvre, H. (1978b). El Derecho a la Ciudad. Barcelona: Ediciones Península.

Linares, S. (2010). Aplicación de Sistemas de Información Geográfica al Estudio de la Segregación Socioespacial Urbana: El caso de la Ciudad de Tandil. In Geografía y Sistemas de Información Geográfica. Aspectos conceptuales y aplicaciones (pp. 329392). Luján: Gustavo Buzai.

Lojkine, J. (1979). El Marxismo, El Estado y la Cuestión Urbana. México: Siglo Veintiuno Editores, S.A.

López, A. (2016). Pobreza e Integración de las Calles. Una Aproximación al Municipio de Ibagué. In Simposio Internacional "Derecho a la Ciudad" ¿Nuevas Agendas Urbanas? Hacia ONU Habitat III. Bogotá D.C: Instituto de Estudios Urbanos y territoriales, Universidad Nacional de Colombia.

Marmolejo, C., \& Batista-Dória, N. J. (2011). Estructura urbana y segregación socioresidencial: un análisis para Maceió-Alagoas, Brasil. Papeles de Poblacion, 70, 247-286.

Martori i Cañas, J. C., \& Hoberg, K. (2004). Indicadores Cuantitativos de Segregación Residencial. El Caso de la Población Inmigrante en Barcelona. REVISTA ELECTRÓNICA DE GEOGRAFÍA Y CIENCIAS SOCIALES, 8(169). Retrieved from http://www.ub.edu/geocrit/sn/sn-169.htm

Martori, J. C., Hoberg, K., \& Surinach, J. (2006a). Poblaci??n inmigrante y espacio urbano. Indicadores de segregaci??n y pautas de localizaci??n. Eure, 32(97), 49-62. https://doi.org/10.4067/S0250-71612006000300004

Martori, J. C., Hoberg, K., \& Surinach, J. (2006b). Población inmigrante y espacio urbano. Indicadores de segregación y pautas de localización. Eure, 32(97), 49-62. https://doi.org/10.4067/S0250-71612006000300004

Massey, D., \& Denton, N. (1988). The Dimensions of Residential Segregation. Social Forces, $\quad 67(2), \quad 281-315 . \quad$ Retrieved from http://isites.harvard.edu/fs/docs/icb.topic98848.files/massey.denton.pdf

Medina, C., Morales, L., \& Núñez, J. (2008). Quality of Life in Urban Neighborhoods in Colombia: The Cases of Bogotá and Medellín. Borradores de Economía, (536).

Molina, L. (2008). Barrancabermeja: Segregación socioespacial y desequilibrios funcionales. Cuadernos de Vivienda y Urbanismo, 1(2), 332-347. Retrieved from http://scholar.google.com/scholar?hl=en\&btnG=Search\&q=intitle:Barrancabermeja+: + segregaci? $\mathrm{n}+$ socioespacial $+\mathrm{y}+$ desequilibrios + funcionales $\# 0$

Molinatti, F. (2013). Segregación residencial socioeconómica en la ciudad de Córdoba (Argentina): Tendencias y patrones espaciales. INVI, 28, 61-94. Retrieved from http://revistainvi.uchile.cl/index.php/INVI/article/view/778/1107 
Monkkonen, P. (2012). La segregación residencial en el México urbano: Niveles y patrones. Eure, 38(114), 125-146.

Morril, R. (1991). On the measure of geographic segregation. Geography Research Forum, 11, 25-36. Retrieved from http://raphael.geography.ad.bgu.ac.il/ojs/index.php/GRF/article/viewFile/91/87

Moura, R. (2003). Inversiones urbanas en el contexto de la competitividad y globalización: los eventos en Curitiba. EURE (Santiago), 29(86), 51-68. https://doi.org/10.4067/S0250-71612003008600003

Ortiz, J., Escolano, S., \& Moreno, R. (2017). Transformación del espacio social en el gran Santiago: ¿Un proceso territorial homogéneo? Revista Geográfica de Valparaíso, 54(August 2018), 1-12. Retrieved from http://www.revistageografica.cl/index.php/revgeo/article/view/23

Pereyra, O. (2006). Forma urbana y segregación residencial en lima. Debates En Sociología, (31).

Prieto, M. (2012). Segregación Socio-residencial en Ciudades Intermedias. El Caso de Bahía Blanca - Argentina. Breves Contribuciones Del Instituto de Estudios Geográficos, (23), 129-156.

Prieto, M., \& Formiga, N. (2010). Aportes para el análisis territorial de la segregación socio residencial en la ciudad de Bahía Blanca-Argentina. In XI "Seminario Internacional Red Iberoa- mericana de Investigadores en Globalización y Territorio (RII). Mendoza.

Prieto, M., \& Formiga, N. (2011). Segregación Socio-residencial en Ciudades Intermedias. El Caso de Bahía Blanca - Argentina. In XIII Conferencia Iberoamericana de Sistemas de Información Geográfica. Toluca.

Pujol M, R., Sánchez H, L., \& Pérez M, E. (2011). La segregación sociaL como determinante del desarroLLo urbano. barrios cerrados y autosegregación en Las ciudades de san José y Heredia, costa rica. Ciencias Económicas, 29(1), 445-476. Retrieved from http://www.latindex.ucr.ac.cr/econ-29-1/economicas-29-1-20.pdf

Reardon, S., \& O'Sullivan, D. (2004). Measures of Spatial Segregation. Sociological Methodology, 34(1), 121-162. https://doi.org/10.1111/j.0081-1750.2004.00150.x

Ríos, M. (2010). Segregación Residencial; el Problema Social Desde la Perspectiva Económica y Urbana. Universidad Nacional de Colombia. Bogotá, Colombia.

Ruiz-Tagle, J. (2016). La persistencia de la segregación y la desigualdad en barrios socialmente diversos: Un estudio de caso en La Florida, Santiago. Eure, 42(125), 81108. https://doi.org/10.4067/S0250-71612016000100004

Ruiz-Tagle, J., \& López, E. (2014). El estudio de la segregación residencial en Santiago de Chile : revisión crítica de algunos problemas metodológicos y conceptuales. EURE, 40(119), 25-48.

Sabatini, F. (2003). La segregación social del espacio en las ciudades de América Latina. Banco Interamericano de Desarrollo, 1-41. Retrieved from http://www.iadb.org.uy/sds/doc/SOCSabatiniSegregacion.pdf

Sabatini, F., \& Cáceres, G. (2005). Relación entre Promoción Inmobiliaria y Segregación Residencial: Giros Insospechados de la Ciudad Latinoaméricana. Lincoln Institute of Land Policy. https://doi.org/10.1017/CBO9781107415324.004

Sabatini, F., Cáceres, G., \& Cerda, J. (2001). Segregación residencial en las principales ciudades chilenas: Tendencias de las tres últimas décadas y posibles cursos de acción. 
EURE, XXVII. https://doi.org/http://dx.doi.org/10.4067/S0250-71612001008200002

Sabatini, F., \& Sierralta, C. (2006). Medição da segregação residencial : meandros teóricos e metodológicos e especificidade latino-americana. In J. M. Pinto da Cunha (Ed.), Novas Metrópoles Paulistas - População, vulnerabiliade e segregação (pp. 169-195). Campinas. Retrieved from http://www.nepo.unicamp.br/publicacoes/livros/vulnerabilidade/index.htm

Sabatini, F., Wormald, G., Sierralta, C., \& Peters, P. (2008). Segregación Residencial en Santiago: Tendencias 1992-2002 y efectos vinculados con su escala geográfica. In F. Sabatini, R. Salcedo, \& G. Wormald (Eds.), Tendencias Segregación en las Principales Ciudades Chilenas. Santiago de Chile: Instituto Nacional de Estadísticas, Pontificia Universidad Católica de Chile.

Saraví, G. (2008). Mundos aislados: segregación urbana y desigualdad en la ciudad de México. EURE (Santiago), 34(103), 93-110. https://doi.org/10.4067/S025071612008000300005

Secretaría Distrital de Planeación. (2007). Segregación Socioeconómica en el Espacio Urbano de Bogotá D.C. Universidad Nacional de Colombia. Bogotá D.C.

Secretaría Distrital de Planeación. (2011). Segregación Socioespacial En Bogotá 2011. Indicadores $y$ Medición. Bogotá D.C. Retrieved from http://es.scribd.com/doc/94922064/Boletn-39-SEGREGACIN

Secretaría Distrital de Planeación. (2013). Segregación Socioeconómica en el Espacio Urbano de Bogotá D.C. Universidad Nacional de Colombia, Secretaría Distrital de Planeación. Bogotá D.C: Secretaría Distrital de Planeación, Universidad Nacional de Colombia.

Shevky, E., \& Bell, W. (1955). Social area analysis: Theory, illustrative application and computational procedures. Stanford: Standford University Press.

Shevky, E., \& Williams, M. (1949). The social area of Los Angeles: analysis and typology. Berkeley: University of California Press.

Torres, C., Gaviria, A., Zuñiga, D., Vargas, J., Nieto, D., \& Bustos, S. (2009). Ciudad informal colombiana Barrios construidos por la gente. Universidad Nacional de Colombia.

Torres, P., \& Caicedo, C. (2015). Las ciudades intermedias con mayor potencial en Colombia: Un sistema de identificación. Banco Interamericano de Desarrollo. Departamento de Países del Grupo Andino. Banco Interamericano de Desarrollo.

Valdés, E. (2007). Fragmentación y segregación urbana. Aportes teóricos para el análisis de casos en la ciudad de Córdoba. Alfilo. Revista digital de la Facultad de Filosofía y Humanidades (Vol. 3 ). http://sistemamid.com/panel/uploads/biblioteca/7097/7128/7129/83441.pdf

Vargas D, I., Jiménez M, E., Grindlay M, A., \& Torres T, C. (2010). Procesos de Mejoramiento Barrial Participativo en Asentamientos Informales: Propuestas de Integración en la Ciudad de Ibagué (Colombia). Revista Invi, $N^{\circ} 25(68), 59-96$. https://doi.org/http://dx.doi.org/10.4067/S0718-83582010000100003

Velasquez, C. (2011). Localización y Distribución de la Vivienda Social en la Ciudad de Medellín. Una Mirada Desde la Segregación Espacial. Universidad Nacional de Colombia, Sede Medellín.

Watts, M. (2005). Conceptualising and measuring spatial segregation: the state of play. 


\section{ANEXOS}

Anexo 1. Índices no espaciales de la segregación residencial por sectores en el municipio de Ibagué, 1993-2005

\begin{tabular}{|c|c|c|c|c|c|c|c|c|c|c|c|}
\hline \multirow{2}{*}{ DIMENSION } & \multirow{2}{*}{ VARIABLES } & \multicolumn{5}{|c|}{ ÍNDICES DE SEGREGACIÓN, 1993} & \multicolumn{5}{|c|}{ ÍNDICES DE SEGREGACIÓN, 2005} \\
\hline & & IS & IS(adj) & $\mathbf{x P x}$ & Eta2 & DEL & IS & IS (adj) & XPx & Eta2 & DEL \\
\hline \multirow{6}{*}{$\begin{array}{l}\text { Socio- } \\
\text { Económica }\end{array}$} & $\begin{array}{l}\text { Jefe de Hogar con Primaria } \\
\text { Completa }\end{array}$ & 0,0671 & 0,0603 & 0,0522 & 0,0017 & 0,8009 & 0,0875 & 0,0796 & 0,0551 & 0,0026 & 0,7686 \\
\hline & $\begin{array}{l}\text { Jefe de Hogar con Secundaria } \\
\text { Completa }\end{array}$ & 0,1652 & 0,1571 & 0,0362 & 0,0048 & 0,8128 & 0,0885 & 0,0819 & 0,0402 & 0,0019 & 0,7761 \\
\hline & $\begin{array}{l}\text { Jefe de Hogar con Posgrado } \\
\text { Completa }\end{array}$ & 0,2953 & 0,276 & 0,0567 & 0,0233 & 0,8162 & 0,2601 & 0,2365 & 0,0791 & 0,0253 & 0,7685 \\
\hline & $\begin{array}{l}\text { Jefe de Hogar sin Ningún Nivel } \\
\text { Educativo }\end{array}$ & 0,2107 & 0,2063 & 0,0157 & 0,0034 & 0,7868 & 0,1961 & 0,1911 & 0,0171 & 0,0031 & 0,7774 \\
\hline & Jefe de Hogar Desempleado & 0,1052 & 0,1038 & 0,0066 & 0,0005 & 0,7995 & 0,1339 & 0,131 & 0,0151 & 0,0015 & 0,7651 \\
\hline & $\begin{array}{l}\text { Menores que no asisten a alguna } \\
\text { institución Educativa }\end{array}$ & 0,1856 & 0,1774 & 0,0406 & 0,0074 & 0,7934 & 0,1666 & 0,1559 & 0,06 & 0,0089 & 0,7641 \\
\hline \multirow{3}{*}{ Habitacional } & $\begin{array}{l}\text { Vivienda sin conexión a la red de } \\
\text { desagüe pública (alcantarillado) }\end{array}$ & 0,2795 & 0,247 & 0,1046 & 0,0408 & 0,7736 & 0,3465 & 0,3348 & 0,0319 & 0,0166 & 0,7619 \\
\hline & $\begin{array}{l}\text { Vivienda sin conexión a la red de } \\
\text { agua corriente pública (acueducto) }\end{array}$ & 0,3855 & 0,3795 & 0,0198 & 0,0114 & 0,7915 & 0,3146 & 0,3115 & 0,0159 & 0,0072 & 0,7789 \\
\hline & $\begin{array}{l}\text { Vivienda sin conexión a la red de } \\
\text { electricidad pública (Energía } \\
\text { eléctrica) }\end{array}$ & 0,2933 & 0,2695 & 0,0705 & 0,0295 & 0,7924 & 0,3169 & 0,3115 & 0,0165 & 0,0069 & 0,7809 \\
\hline \multirow{4}{*}{ Espacial } & Salud & 0,5614 & 0,5239 & 0,2067 & 0,1352 & 0,8884 & 0,5234 & 0,4814 & 0,1765 & 0,1107 & 0,8716 \\
\hline & Educación & 0,4132 & 0,3115 & 0,6595 & 0,2413 & 0,8434 & 0,379 & 0,2493 & 0,6771 & 0,1928 & 0,8 \\
\hline & Deporte & 0,4567 & 0,3572 & 0,4842 & 0,2556 & 0,8475 & 0,4014 & 0,2786 & 0,4244 & 0,1951 & 0,817 \\
\hline & Cultura & 0,7911 & 0,7698 & 0,3677 & 0,328 & 0,9669 & 0,8714 & 0,833 & 0,3671 & 0,3399 & 0,9787 \\
\hline
\end{tabular}

Fuente: Elaboración propia, según datos censales del DANE de 1993 y 2005. 
Anexo 2. Índices no espaciales de la segregación residencial por secciones en el municipio de Ibagué, 1993-2005

\begin{tabular}{|c|c|c|c|c|c|c|c|c|c|c|c|}
\hline \multirow{2}{*}{ DIMENSION } & \multirow{2}{*}{ VARIABLES } & \multicolumn{5}{|c|}{ ÍNDICES DE SEGREGACIÓN, 1993} & \multicolumn{5}{|c|}{ ÍNDICES DE SEGREGACIÓN, 2005} \\
\hline & & IS & IS(adj) & $\mathrm{xPx}$ & Eta2 & DEL & IS & IS(adj) & $\mathrm{XPx}$ & Eta2 & DEL \\
\hline \multirow{6}{*}{$\begin{array}{l}\text { Socio- } \\
\text { Económica }\end{array}$} & Jefe de Hogar con Primaria Completa & 0,1025 & 0,1009 & 0,0539 & 0,0036 & 0,8387 & 0,1334 & 0,1311 & 0,0584 & 0,0059 & 0,8028 \\
\hline & $\begin{array}{l}\text { Jefe de Hogar con Secundaria } \\
\text { Completa }\end{array}$ & 0,213 & 0,2113 & 0,0395 & 0,0081 & 0,8488 & 0,1411 & 0,1392 & 0,0431 & 0,0047 & 0,8083 \\
\hline & Jefe de Hogar con Posgrado Completa & 0,3933 & 0,3896 & 0,0715 & 0,0385 & 0,8501 & 0,3404 & 0,3355 & 0,0937 & 0,0407 & 0,813 \\
\hline & $\begin{array}{l}\text { Jefe de Hogar sin Ningún Nivel } \\
\text { Educativo }\end{array}$ & 0,2773 & 0,2764 & 0,0182 & 0,0059 & 0,8455 & 0,2704 & 0,2692 & 0,0199 & 0,006 & 0,8137 \\
\hline & Jefe de Hogar Desempleado & 0,1658 & 0,1654 & 0,0072 & 0,001 & 0,8399 & 0,1915 & 0,1906 & 0,017 & 0,0034 & 0,8047 \\
\hline & $\begin{array}{l}\text { Menores que no asisten a alguna } \\
\text { institución Educativa }\end{array}$ & 0,2201 & 0,2185 & 0,0433 & 0,0106 & 0,8298 & 0,2226 & 0,2197 & 0,0661 & 0,0151 & 0,8021 \\
\hline \multirow{3}{*}{ Habitacional } & $\begin{array}{l}\text { Vivienda sin conexión a la red de } \\
\text { desagüe pública (alcantarillado) }\end{array}$ & 0,3556 & 0,3481 & 0,1425 & 0,0811 & 0,8249 & 0,5327 & 0,5298 & 0,0581 & 0,0431 & 0,8134 \\
\hline & $\begin{array}{l}\text { Vivienda sin conexión a la red de agua } \\
\text { corriente pública (acueducto) }\end{array}$ & 0,4556 & 0,4542 & 0,0317 & 0,0232 & 0,8575 & 0,4741 & 0,4724 & 0,0316 & 0,0229 & 0,8253 \\
\hline & $\begin{array}{l}\text { Vivienda c sin conexión a la red de } \\
\text { electricidad pública (Energía eléctrica) }\end{array}$ & 0,3564 & 0,3519 & 0,0866 & 0,046 & 0,8437 & 0,4886 & 0,4864 & 0,0482 & 0,0389 & 0,8241 \\
\hline \multirow{4}{*}{ Espacial } & Salud & 0,7322 & 0,724 & 0,3295 & 0,2706 & 0,9821 & 0,7158 & 0,6978 & 0,3078 & 0,2486 & 0,9696 \\
\hline & Educación & 0,4651 & 0,4394 & 0,7055 & 0,3341 & 0,9375 & 0,469 & 0,4153 & 0,7165 & 0,3213 & 0,8959 \\
\hline & Deporte & 0,5472 & 0,5225 & 0,5705 & 0,383 & 0,9444 & 0,5248 & 0,4786 & 0,524 & 0,3352 & 0,9208 \\
\hline & Cultura & 0,8653 & 0,8623 & 0,4189 & 0,3833 & 0,9964 & 0,904 & 0,8956 & 0,4613 & 0,43 & 0,9931 \\
\hline
\end{tabular}

Fuente: Elaboración propia, según datos censales del DANE de 1993 y 2005. 